\title{
Analysis of Oxysterols by Electrospray Tandem Mass Spectrometry
}

\author{
William J. Griffiths and Yuqin Wang \\ Department of Pharmaceutical and Biological Chemistry, The School of Pharmacy, University of London, \\ London, United Kingdom
}

\author{
Gunvor Alvelius, Suya Liu, Karl Bodin, and Jan Sjövall \\ Department of Medical Biochemistry and Biophysics, Karolinska Institutet, Stockholm, Sweden
}

\begin{abstract}
Oxysterols are oxygenated derivatives of cholesterol. They are intermediates in cholesterol excretion pathways and may also be regarded as transport forms of cholesterol. The introduction of additional hydroxyl groups to the cholesterol skeleton facilitates the flux of oxysterols across the blood brain barrier, and oxysterols have been implicated in mediating a number of cholesterol-induced metabolic effects. Oxysterols are difficult to analyze by atmospheric pressure ionization mass spectrometry on account of the absence of basic or acidic functional groups in their structures. In this communication, we report a method for the derivatization and analysis of oxysterols by electrospray mass spectrometry. Oxysterols with a $3 \beta$-hydroxy- $\Delta^{5}$ structure were converted by cholesterol oxidase to 3-oxo- $\Delta^{4}$ steroids and then derivatized with the Girard P reagent to give Girard P hydrazones, which were subsequently analyzed by tandem mass spectrometry. The improvement in sensitivity for the analysis of 25-hydroxycholesterol upon oxidation and derivatization was over 1000. (J Am Soc Mass Spectrom 2006, 17, 341-362) (c) 2006 American Society for Mass Spectrometry
\end{abstract}

$\mathrm{T}$ The introduction of an oxygen function in the cholesterol $\left(C^{5}-3 \beta\right.$-ol $)$ molecule with the formation of an oxysterol is the first step in cholesterol degradation pathways [1,2]. The quantitatively most important catabolic pathway is the subsequent conversion of the oxysterol into water-soluble bile acids. However, other oxysterols are intermediates in the formation of steroid hormones. Oxysterol formation can occur in many tissues and organs, and conversion of an oxysterol to a bile acid is not restricted to the liver [3-7]. Hormonally active steroids can also be synthesized from cholesterol outside the endocrine organs. Some oxysterols are ligands to nuclear receptors, e.g., the liver $\mathrm{X}$ receptor (LXR) $\alpha$ and $\beta$, and are considered to have important roles in the regulation of cholesterol and lipid metabolism and homeostasis [8-15]. Some oxysterols have been proposed to mediate inflammatory events in the development of atherosclerotic lesions [16]. A variety of oxysterols are found in blood and tissues, exemplified by 27-hydroxycholesterol $\left(C^{5}-3 \beta, 27-\right.$ diol $), 7 \alpha$ hydroxycholesterol ( $C^{5}-3 \beta, 7 \alpha$-diol), 24S-hydroxycho-

Published online January 25, 2006

Address reprint requests to Dr. W. J. Griffiths, Department of Pharmaceutical and Biological Chemistry, The School of Pharmacy, University of London, 29-39 Brunswick Square, London WC1N 1AX, United Kingdom. E-mail: william.griffiths@ulsop.ac.uk

This article was presented at the 52nd American Society for Mass Spectrometry Conference, May 23-27, 2004, Nashville, Tennessee, and at the 20th Asilomar Conference on Mass Spectrometry, October 15-18, 2004, Pacific Grove, California. lesterol $\left(C^{5}-3 \beta, 24 S\right.$-diol $)$, and $4 \beta$-hydroxycholesterol $\left(C^{5}-3 \beta, 4 \beta\right.$-diol) (see Scheme 1 for steroid skeleton and numbering system). The levels in plasma of healthy subjects vary between about 30 and $150 \mathrm{ng} / \mathrm{mL}$. Minor oxysterols include 25-hydroxycholesterol $\left(\mathrm{C}^{5}\right.$ $3 \beta, 25$-diol), $7 \beta$-hydroxycholesterol $\left(C^{5}-3 \beta, 7 \beta\right.$-diol $)$, 7-oxocholesterol ( $C^{5}$-3 $\beta$-ol-7-one), cholesterol-5,6epoxides (C-3 $\beta$-ol-5,6-epoxide), cholestane-3,5,6-triols (C-3 $\beta, 5,6$-triol) [2]. The levels of these compounds are usually below $10 \mathrm{ng} / \mathrm{mL}$. Other oxysterols that have been found, e.g. in brain, include 20-hydroxycholesterol $\left(C^{5}-3 \beta, 20\right.$-diol) and 22-hydroxycholesterol $\left(C^{5}-3 \beta, 22\right.$-diol $)[17,18]$. There is always some doubt with respect to the origin of the minor oxysterols as they can be formed by non-enzymatic oxidation of cholesterol [2]. Oxysterols are present in only trace amounts in biological systems, where the excess of cholesterol is invariably more than three orders of magnitude.

Oxysterols with a $3 \beta, 7 \alpha$-dihydroxy-5-ene structure can be oxidized to the corresponding $7 \alpha$-hydroxy-4-en3-ones, and 27-hydroxylated oxysterols can be converted to 27-carboxylic acids both in the liver and extrahepatically. Examples of such metabolites occurring in human circulation are $7 \alpha$-hydroxycholest-4-en3-one ( $C^{4}-7 \alpha$-ol-3-one), 3 $\beta$-hydroxycholest-5-en-27-oic acid ( $\mathrm{CA}^{5}-3 \beta$-ol), 3 $\beta, 7 \alpha$-dihydroxycholest-5-en-27-oic acid ( $\mathrm{CA}^{5}-3 \beta, 7 \alpha$-diol), and $7 \alpha$-hydroxy-3-oxo-cholest-4en-27-oic acid ( $\mathrm{CA}^{4}-7 \alpha$-ol-3-one) (Scheme 1). Because of their structures and since some of them have regulatory 


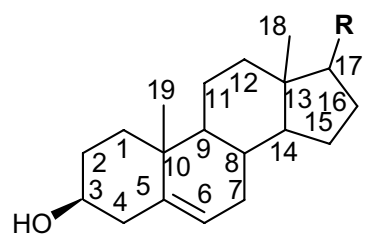

3ß-hydroxy- $\Delta^{5}$

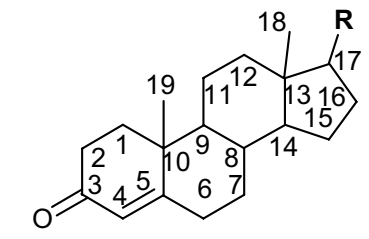

$3-0 \times 0-\Delta^{4}$
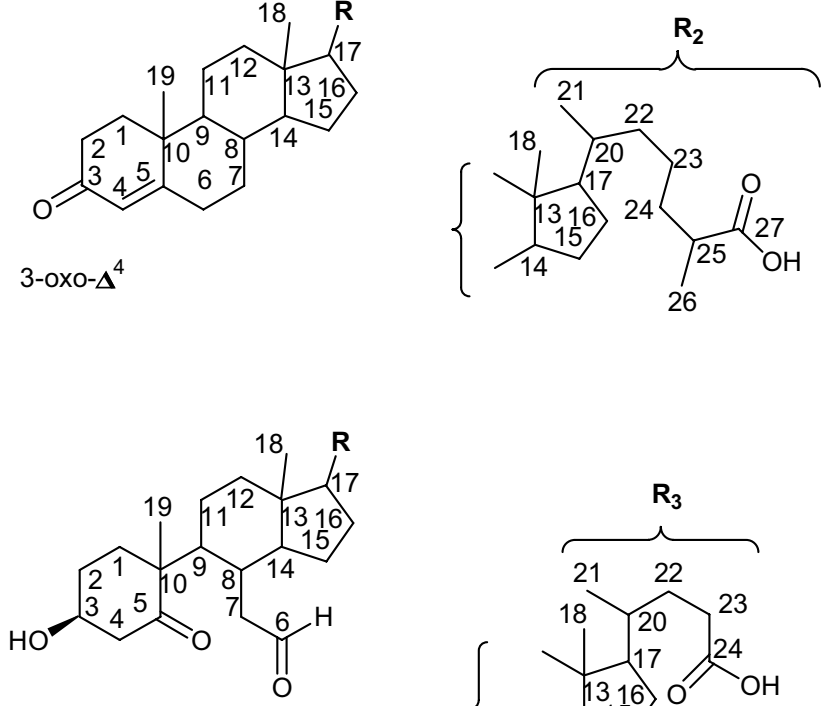

3ß-hydroxy-5-oxo-5,6-seco-6-al:

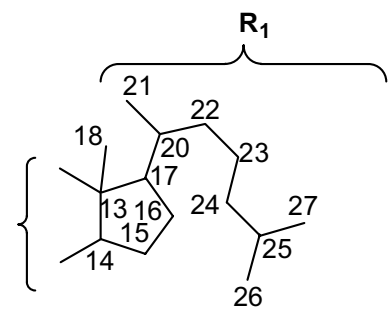

(formed from 27-hydroxycholesterol [23]) originates mostly from the lung [7]. 24S-Hydroxycholesterol in the human circulation originates mainly from the brain, where it is formed by the action of CYP46A1 [24]. While $7 \alpha$-hydroxycholesterol, 27-hydroxycholesterol and $3 \beta-$ hydroxycholest-5-en-27-oic acid are efficiently converted into bile acids in the liver, about half of the 24S-hydroxycholesterol formed in humans is excreted in bile in a sulphated or glucuronidated form. This illustrates that oxysterols, besides being in the free form (and as fatty acid esters), can occur in different conjugated forms. It has been shown recently that that 24S-hydroxycholesterol can be further metabolized into 24,27-dihydroxycholesterol $\left(C^{5}-3 \beta, 24,27\right.$-triol) in man [25]. $4 \beta$-Hydroxycholesterol is formed by the action of CYP3A4 [26], the major cytochrome P450 in human liver. The metabolic end products of $4 \beta$-hydroxycholesterol have yet to be defined.

Besides known naturally occurring oxysterols, a large number of synthetic oxysterols have been shown to be potential ligands to nuclear receptors. It is not known if some of these occur naturally, and there is a need for methods to make comprehensive studies of the nature and levels of oxysterols in tissues and body fluids. This is illustrated by the recent identification of novel oxysterols, formed from cholesterol by the action of ozone, in human tissues [27-30]. Evidence has been presented for their involvement in the mediation of inflammatory processes associated with the development of atherosclerotic lesions [28], and in the initiation of protein misfolding as occurs in several neurological diseases [29]. Of these products, $3 \beta$-hydroxy-5-oxo-5,6secocholestan-6-al (5,6-seco-sterol), a ketoaldehyde, and its aldol condensation product both contain a reactive aldehyde group (Scheme 1). Incubation of 5,6-secosterol, or its aldol, with amyloid $\beta$ peptide $(\mathrm{A} \beta)$ leads to amyloidogenesis, possibly by condensation with amino groups in the peptide [29]. The levels of the 5,6-secosterol and its aldol were surprisingly high in brain of patients with Alzheimer's disease and healthy subjects [combined seco-sterol levels $\sim 0.44 \mathrm{pmol} / \mathrm{mg} \quad(\sim 180$ $\mathrm{ng} / \mathrm{g})$ and $\sim 0.35 \mathrm{pmol} / \mathrm{mg}(\sim 150 \mathrm{ng} / \mathrm{g})$, respectively]. Biologically active oxysterols are also formed during ozonolysis of cholesterol in lung surfactant [30]. Pulfer and Murphy [30] identified the major cholesterol derived ozonolysis product in lung surfactant as $5 \beta, 6 \beta-$ epoxycholesterol (C-3 $\beta$-ol-5 $\beta, 6 \beta$-epoxide). In studies of the metabolism of this oxysterol in lung epithelial cells they found small amounts of the expected metabolite cholestane- $3 \beta, 5 \alpha, 6 \beta$-triol (C- $3 \beta, 5 \alpha, 6 \beta$-triol), and more abundant levels of the unexpected metabolite $3 \beta, 5 \alpha$ dihydroxycholestan-6-one (C-3 $\beta, 5 \alpha$-diol-6-one). Significantly, both $5 \beta, 6 \beta$-epoxycholesterol and $3 \beta, 5 \alpha$-dihydroxycholestan-6-one were shown to be cytotoxic to human bronchial epithelial cells.

Traditionally, oxysterols have been analyzed by isotope-dilution gas-chromatography-mass spectrometry (GC-MS) [31, 32]. However, high-performance liquid

chromatography (HPLC) methods have been intro- specificity and is present in most tissues [1, 2]. The $3 \beta$-hydroxycholest-5-en-27-oic acid in human plasma 
duced in which oxysterols are converted to their 3-oxo- $\Delta^{4}$ derivatives which are then analyzed and detected using their UV chromophore at 205-210 or 240 $\mathrm{nm}[33,34]$. In the current study, we have followed an analogous methodology whereby steroids with a $3 \beta-$ hydroxy- $\Delta^{5}$ structure have been converted to their 3 -oxo- $\Delta^{4}$ oxidation products by treatment with cholesterol oxidase [35-37], and then reacted with Girard P (GP) reagent to give GP hydrazones [38, 39]. Girard hydrazones possess a quaternary nitrogen and are readily analyzed by electrospray (ES) mass spectrometry [35-45]. Furthermore, tandem mass spectrometry (MS/MS) provides high sensitivity and structural information for GP hydrazone analysis. Griffiths et al. were able to obtain structurally informative ES-MS/MS spectra for steroid GP hydrazones from sub-pg quantities of sample $[38,39]$. In the current study we have explored the MS/MS fragmentation patterns of a series of oxysterol GP hydrazones, and evaluated the potential of these derivatives for analyzing oxysterols in biological samples. We have also optimized the enzymatic conversion of oxysterols to their 3-oxo- $\Delta^{4}$ analogs under conditions compatible with subsequent ES analysis, and also optimized the derivatization reaction so as to be suitable for labile steroids, i.e., 7-hydroxy- $\Delta^{4}$-3-oxosteroids. The methodology was tested in an analysis of an oxysterol fraction from rat brain.

\section{Experimental}

\section{Materials}

Solvents were of analytical grade. Water was from a Milli-Q water system (Millipore, Molsheim, France). The oxysterols 7 $\beta$-hydroxycholesterol, 24S-hydroxycholesterol, 20R,22R-dihydroxycholesterol ( $C^{5}-3 \beta, 20 R, 22 R$-triol), and 22-oxocholesterol $\left(C^{5}-3 \beta\right.$-ol-22-one) were kind gifts from Professor I. Björkhem of the Division of Clinical Chemistry, Karolinska Institutet. Other oxysterols and steroids, i.e., 25-hydroxycholesterol, 27-hydroxycholesterol, [16,16,17(or 20),22,22,23,23- $\left.{ }^{2} \mathrm{H}_{7}\right] 27$-hydroxycholesterol $\left(\left[{ }^{2} \mathrm{H}_{7}\right] \mathrm{C}^{5}-3 \beta, 27\right.$-diol), $7 \alpha, 25$-dihydroxycholesterol $\left(\mathrm{C}^{5}\right.$ $3 \beta, 7 \alpha, 25$-triol $), 7 \beta, 25$-dihydroxycholesterol $\left(C^{5}-3 \beta, 7 \beta, 25-\right.$ triol), $\quad 7 \alpha, 27$-dihydroxycholesterol $\quad\left(C^{5}-3 \beta, 7 \alpha, 27\right.$-triol $)$, $[16,16,17$ (or 20$\left.), 22,22,23,23-{ }^{2} \mathrm{H}_{7}\right] \quad 7 \alpha, 27$-dihydroxycholesterol $\left(\left[{ }^{2} \mathrm{H}_{7}\right] \mathrm{C}^{5}-3 \beta, 7 \alpha, 27\right.$-triol), [16,16,17(or 20),22,22,23,23$\left.{ }^{2} \mathrm{H}_{7}\right] 3 \beta$-hydroxycholest-5-en-27-oic acid $\left({ }^{2} \mathrm{H}_{7}\right] \mathrm{CA}^{5}-3 \beta$-ol), $\left[16,16,17\right.$ (or 20),22,22,23,23- $\left.{ }^{-2} \mathrm{H}_{7}\right] 3 \beta, 7 \alpha$-dihydroxycholest5 -en-27-oic acid $\left(\left[{ }^{2} \mathrm{H}_{7}\right] \mathrm{CA}^{5}-3 \beta, 7 \alpha\right.$-diol), [16,16,17(or 20), $\left.22,22,23,23-{ }^{2} \mathrm{H}_{7}\right] 3 \beta, 7 \alpha$-dihydroxycholest-5-en-27-oic acid methyl ester $\left(\left[{ }^{2} \mathrm{H}_{7}\right] \mathrm{CA}^{5}-3 \beta, 7 \alpha\right.$-diol-27-methyl ester), $3 \beta, 7 \beta-$ dihydroxycholest-5-en-27-oic acid $\left(\mathrm{CA}^{5}-3 \beta, 7 \beta\right.$-diol), $3 \beta$ hydroxychol-5-en-24-oic acid (BA $\left.{ }^{5}-3 \beta-\mathrm{ol}\right),\left[2,2,4,4,23-{ }^{2} \mathrm{H}_{5}\right]$ $3 \beta$-hydroxychol-5-en-24-oic acid $\left(\left[{ }^{2} \mathrm{H}_{5}\right] \mathrm{BA}^{5}-3 \beta\right.$-ol), $3 \beta, 7 \alpha$ dihydroxychol-5-en-24-oic acid (BA $-3 \beta, 7 \alpha$-diol), [2,2,4, 4,23- $\left.{ }^{2} \mathrm{H}_{5}\right]$ 3 3 -hydroxychol-5-en-24-oylglycine $\left(\left[{ }^{2} \mathrm{H}_{4}\right] \mathrm{BA}^{5}-\right.$ $3 \beta$-ol-24-oylglycine), cholesterol $\left(\mathrm{C}^{5}-3 \beta\right.$-ol $)$, desmosterol $\left(C^{5}, 24-3 \beta\right.$-ol), sitosterol $\left(C^{5}-24 \beta\right.$-ethyl-3 $\beta$-ol $)$, stigmasterol $\left(\mathrm{C}^{5,22}\right.$-24 $\beta$-ethyl-3 $\beta$-ol), testosterone ( $\mathrm{A}^{4}-17 \beta$-ol-3-one), and $\left[19,19,19-{ }^{2} \mathrm{H}_{3}\right]$ testosterone were from previous studies in the Karolinska laboratory (Table 1) [38, 39, 46].

\section{Oxidation of $3 \beta-H y d r o x y-\Delta^{5}$ Sterols to $3-O x o-\Delta^{4}$ Sterols}

The $3 \beta$-hydroxy- $\Delta^{5}$ sterols (and bile acids and steroids) were oxidized with cholesterol oxidase essentially as described by Brooks et al. [47]. Recombinant, lyophilized, cholesterol oxidase from Brevibacterium was obtained from Roche Diagnostics $\mathrm{GmbH}$, Mannheim, Germany, through the courtesy of Dr. Ingo Preuss. The enzyme from Brevibacterium was selected since, in contrast to the common enzyme from Nocardia, it also catalyzes the oxidation of $3 \beta$-hydroxy- $\Delta^{5}$ steroids of the $\mathrm{C}_{19}$ and $\mathrm{C}_{21}$ series [48]. Steroids of the latter type are important intermediates in steroid hormone biosynthesis with biological functions, e.g., as neurosteroids in brain $[49,50]$. The $3 \beta$-hydroxy- $\Delta^{5}$ sterols $(1 \mu \mathrm{g})$ were dissolved in $50 \mu \mathrm{L}$ of isopropanol, and $10 \mu \mathrm{L}$ of cholesterol oxidase $(1 \mathrm{mg} / \mathrm{mL}, 20 \mathrm{U} / \mathrm{mg}$ protein) in $1 \mathrm{~mL}$ of buffer (50 $\left.\mathrm{mM} \mathrm{KH}_{2} \mathrm{PO}_{4}, \mathrm{pH} 7\right)$ was added; the mixture was incubated at room temperature $\left(25^{\circ} \mathrm{C}\right.$ for 2 to $\left.12 \mathrm{~h}\right)$ and subsequently used as the starting solution for reaction with the GP reagent as described below. In initial experiments designed to study the extent of the oxidation reaction (primarily using bile acids), the enzyme reaction was stopped after overnight incubation by the addition of $1 \mathrm{~mL}$ of methanol, and passed through a Sep-Pak $\mathrm{C}_{18}$ cartridge (100 mg, Waters, Milford, MA) prepared in water. The effluent and a 1 $\mathrm{mL}$ water-wash were combined and passed again through the same Sep-Pak cartridge. After washing with $1 \mathrm{~mL}$ of $20 \%$ methanol the 3-oxo- $\Delta^{4}$ sterols were eluted with $2 \times 1 \mathrm{~mL}$ of methanol, and $1 \mathrm{~mL}$ chloroform $/$ methanol, 1:1 (vol/vol), if needed.

\section{Derivatization of Oxosterols}

The derivatization of oxosterols to GP hydrazones was carried out essentially as described by Shackleton et al. [40] and by Wheeler [51]. The reaction mixture from the oxidation step above was used directly after the incubation without any further treatment. The oxidation mixture, $1 \mathrm{~mL}$ (50 $\mathrm{mM}$ phosphate buffer, $5 \%$ isopropanol, $10 \mu \mathrm{g}$ enzyme and $1 \mu \mathrm{g}$ sterols) was diluted with 2 $\mathrm{mL}$ of methanol to give a $70 \%$ methanol solution, and $150 \mathrm{mg}$ of GP hydrazine (Sigma-Aldrich, Poole, Dorset, UK) and $150 \mu \mathrm{L}$ of glacial acetic acid were added. The mixture was left at room temperature overnight.

In initial studies, when the derivatization reaction was applied to reference compounds, the next step was to dry the steroid GP hydrazone under a stream of nitrogen gas and reconstitute in a solution of $10 \%$ aqueous methanol $(1 \mathrm{~mL})$. The steroid GP hydrazone was then separated from excess reagent by extraction on a Sep-Pak $C_{18}$ cartridge. After washing with $10 \%$ 
Table 1. Steroids and oxysterols analyzed as GP hydrazones

\begin{tabular}{|c|c|c|c|c|}
\hline Name & Abbreviation & Oxidation product & Mass of GP & Cmpd (MS/MS Fig $\left.{ }^{4}\right)$ \\
\hline Cholesterol & $C^{5}-3 \beta$-ol & $\mathrm{C}^{4}$-3-one & 518.41 & $I(3 c)$ \\
\hline Desmosterol & $\mathrm{C}^{5,24}-3 \beta$-ol & $C^{4,24}$-3-one & 516.40 & II (S-4b) \\
\hline Sitosterol & 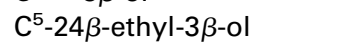 & $C^{4}$-24 $\beta$-ethyl-3-one & 546.44 & III (S-4c) \\
\hline Stigmasterol & 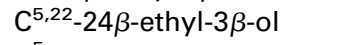 & $\mathrm{C}^{4,22}$-24 $\beta$-ethyl-3-one & 544.43 & IV (S-4d) \\
\hline $7 \beta$-hydroxycholesterol & $\mathrm{C}^{5}-3 \beta, 7 \beta$-diol & $\mathrm{C}^{4}-7 \beta$-ol-3-one & 534.41 & $V(2 e)$ \\
\hline 24-hydroxycholesterol & $C^{5}-3 \beta, 24$-diol & $\mathrm{C}^{4}$-24-ol-3-one & 534.41 & VI (2a) \\
\hline 25-hydroxycholesterol & $C^{5}-3 \beta, 25$-diol & $\mathrm{C}^{4}$-25-ol-3-one & 534.41 & VII $(2 c)$ \\
\hline 27-hydroxycholesterol & $C^{5}-3 \beta, 27$-diol & $\mathrm{C}^{4}-27-\mathrm{ol}-3-\mathrm{one}$ & 534.41 & VIII (2d) \\
\hline $\begin{array}{l}{[16,16,17 \text { (or } 20), 22,22,23,} \\
\left.23-{ }^{2} \mathrm{H}_{7}\right] 27- \\
\text { hydroxycholesterol }\end{array}$ & $\begin{array}{l}{[16,16,17 \text { (or } 20), 22,22,23} \\
\left.\quad 23-{ }^{2} \mathrm{H}_{7}\right] \mathrm{C}^{5}-3 \beta, 27- \\
\quad \text { diol }\end{array}$ & $\begin{array}{l}{[16,16,17 \text { (or 20),22,22,23, }} \\
\left.23-{ }^{2} \mathrm{H}_{7}\right] \mathrm{C}^{4}-27-\text { ol-3- } \\
\text { one }\end{array}$ & 541.45 & IX \\
\hline 22-oxocholesterol & $C^{5}-3 \beta$-ol-22-one & $C^{4}-3,22$-dione & $532.39^{1}$ & $X(2 f)$ \\
\hline 22-oxocholesterol & $C^{5}-3 \beta$-ol-22-one & $\mathrm{C}^{4}$-3,22-dione & $666.46^{2}$ & $X I(2 g)$ \\
\hline 20R,22R-dihydroxycholesterol & $\mathrm{C}^{5}-3 \beta, 20 \mathrm{R}, 22 \mathrm{R}$-triol & $\begin{array}{l}\mathrm{C}^{4}-20 \mathrm{R}, 22 \mathrm{R}-\text { diol-3- } \\
\text { one }\end{array}$ & 550.40 & XII (3b) \\
\hline $7 \alpha, 25$-dihydroxycholesterol & $C^{5}-3 \beta, 7 \alpha, 25$-triol & $C^{4}-7 \alpha, 25$-diol-3-one & 550.40 & XIII (S-1c) \\
\hline $7 \beta, 25$-dihydroxycholesterol & $C^{5}-3 \beta, 7 \beta, 25$-triol & $C^{4}-7 \beta, 25$-diol-3-one & 550.40 & XIV (S-1d) \\
\hline $7 \alpha, 27$-dihydroxycholesterol & $C^{5}-3 \beta, 7 \alpha, 27$-triol & $C^{4}-7 \alpha, 27-$ diol-3-one & 550.40 & $X V(3 a)$ \\
\hline $\begin{array}{l}{[16,16,17(\text { or } 20), 22,22,23,} \\
\left.23-{ }^{2} \mathrm{H}_{7}\right] 7 \alpha, 27- \\
\text { dihydroxycholesterol }\end{array}$ & $\begin{array}{l}{[16,16,17 \text { (or } 20), 22,22,23} \\
\left.23-{ }^{2} \mathrm{H}_{7}\right] \mathrm{C}^{5}- \\
3 \beta, 7 \alpha, 27 \text {-triol }\end{array}$ & $\begin{array}{l}{[16,16,17 \text { (or 20), } 22,22,23} \\
\left.23-{ }^{2} \mathrm{H}_{7}\right] \mathrm{C}^{4}-7 \alpha, 27- \\
\text { diol-3-one }\end{array}$ & 557.44 & $X V I(S-1 b)$ \\
\hline $\begin{array}{l}{[16,16,17 \text { (or } 20), 22,22,23,} \\
\left.23-{ }^{2} \mathrm{H}_{7}\right] 3 \beta \text {-hydroxycholest-5- } \\
\text { en-27-oic acid }\end{array}$ & $\begin{array}{l}{[16,16,17 \text { (or } 20), 22,22,23} \\
\left.23-{ }^{2} \mathrm{H}_{7}\right] \mathrm{CA}^{5}-3 \beta \text {-ol }\end{array}$ & $\begin{array}{l}{[16,16,17 \text { (or } 20), 22,22,23} \\
\left.23-{ }^{2} \mathrm{H}_{7}\right] \mathrm{CA}^{4}-3 \text {-one }\end{array}$ & 555.43 & XVII (S-2a) \\
\hline $\begin{array}{l}{[16,16,17 \text { (or } 20), 22,22,23,} \\
\left.23^{2} \mathrm{H}_{7}\right] 3 \beta, 7 \alpha^{-} \\
\text {dihydroxycholest-5-en-27-oic } \\
\text { acid }\end{array}$ & $\begin{array}{l}{[16,16,17 \text { (or } 20), 22,22,23} \\
\left.23-{ }^{2} \mathrm{H}_{7}\right] \mathrm{CA}^{5}-3 \beta, 7 \alpha^{-} \\
\quad \text { diol }\end{array}$ & $\begin{array}{l}{[16,16,17(\text { or } 20), 22,22,23} \\
\left.\text { 23- }{ }^{2} \mathrm{H}_{7}\right] \mathrm{CA}^{4}-7 \alpha \text {-ol- } \\
\text { 3-one }\end{array}$ & 571.42 & XVIII (S-2b) \\
\hline $\begin{array}{l}{[16,16,17 \text { (or } 20), 22,22,23} \\
\left.23^{2} \mathrm{H}_{7}\right] 3 \beta, 7 \beta- \\
\text { dihydroxycholest-5-en-27-oic } \\
\text { acid }\end{array}$ & $\begin{array}{l}{[16,16,17 \text { (or } 20), 22,22,23} \\
\left.23-{ }^{2} \mathrm{H}_{7}\right] \mathrm{CA}^{5}-3 \beta, 7 \beta- \\
\text { diol }\end{array}$ & $\begin{array}{l}{[16,16,17 \text { (or20),22,22,23, }} \\
\left.\text { 23- }{ }^{2} \mathrm{H}_{7}\right] \mathrm{CA}^{4}-7 \beta \text {-ol- } \\
\text { 3-one }\end{array}$ & 571.42 & $\mathrm{XIX}(\mathrm{S}-2 \mathrm{c})$ \\
\hline $\begin{array}{l}{[16,16,17 \text { (or20),22,22,23, }} \\
\left.23-^{2} \mathrm{H}_{7}\right] 3 \beta, 7 \alpha- \\
\text { dihydroxycholest-5-en-27-oic } \\
\text { acid methyl ester }\end{array}$ & $\begin{array}{l}{[16,16,17 \text { (or } 20), 22,22,23} \\
\left.23-{ }^{2} \mathrm{H}_{7}\right] \mathrm{CA}^{5}-3 \beta, 7 \alpha- \\
\text { diol-27-methyl } \\
\text { ester }\end{array}$ & $\begin{array}{l}{[16,16,17 \text { (or20),22,22,23, }} \\
\left.\text { 23- }{ }^{2} \mathrm{H}_{7}\right] \mathrm{CA}^{4}-7 \alpha \text {-ol- } \\
\text { 3-one-27-methyl } \\
\text { ester }\end{array}$ & 585.44 & $x X$ \\
\hline $\begin{array}{l}{[16,16,17 \text { (or } 20), 22,22,23} \\
\left.23^{2} \mathrm{H}_{7}\right] 3 \beta, 7 \beta- \\
\text { dihydroxycholest-5-en-27-oic } \\
\text { acid methyl ester }\end{array}$ & $\begin{array}{l}{[16,16,17 \text { (or } 20), 22,22,23} \\
\left.23-{ }^{2} \mathrm{H}_{7}\right] \mathrm{CA}^{5}-3 \beta, 7 \beta- \\
\text { diol-27-methyl } \\
\text { ester }\end{array}$ & $\begin{array}{l}{[16,16,17 \text { (or20),22,22,23, }} \\
\left.\text { 23- }{ }^{2} \mathrm{H}_{7}\right] \mathrm{CA}^{4}-7 \beta \text {-ol- } \\
\text { 3-one-27-methyl } \\
\text { ester }\end{array}$ & 585.44 & $X X I(S-2 d)$ \\
\hline $\begin{array}{l}3 \beta \text {-hydroxychol-5-en-24-oic } \\
\text { acid }\end{array}$ & $\mathrm{BA}^{5}-3 \beta$-ol & $\mathrm{BA}^{4}$-3-one & 506.34 & XXII (S-3a) \\
\hline $\begin{array}{l}{\left[2,2,4,4,23-{ }^{2} \mathrm{H}_{5}\right] 3 \beta \text {-hydroxychol- }} \\
\text { 5-en-24-oic acid }\end{array}$ & $\begin{array}{l}{\left[2,2,4,4,23-{ }^{2} \mathrm{H}_{5}\right] \mathrm{BA}^{5}-} \\
\quad 3 \beta \text {-ol }\end{array}$ & $\begin{array}{l}{\left[2,2,4,23-{ }^{2} \mathrm{H}_{4}\right] \mathrm{BA}^{4}-3-} \\
\text { one }\end{array}$ & 510.36 & XXIII (S-3b) \\
\hline $\begin{array}{l}{\left[2,2,4,4,23-{ }^{2} \mathrm{H}_{5}\right] 3 \beta \text {-hydroxychol- }} \\
\text { 5-en-24-oylglycine }\end{array}$ & $\begin{array}{l}{\left[2,2,4,4,23-{ }^{2} \mathrm{H}_{5}\right] \mathrm{BA}^{5}-} \\
3 \beta \text {-ol-24- } \\
\text { oylglycine }\end{array}$ & $\begin{array}{l}{\left[2,2,4,23-{ }^{2} \mathrm{H}_{4}\right] \mathrm{BA}^{4}-3-} \\
\text { one-24-oylglycine }\end{array}$ & 567.38 & XXIV (S-3c) \\
\hline $\begin{array}{l}3 \beta, 7 \alpha \text {-dihydroxychol-5-en-24- } \\
\text { oic acid }\end{array}$ & BA $^{5}-3 \beta, 7 \alpha$-diol & BA $^{4}-7 \alpha$-ol-3-one & 522.33 & $X X V(S-3 d)$ \\
\hline Testosterone $^{3}$ & $A^{4}-17 \beta$-ol-3-one & $A^{4}-17 \beta$-ol-3-one & 422.28 & XXVI \\
\hline
\end{tabular}

aqueous methanol ( $2 \mathrm{~mL}$ ), the GP hydrazone was eluted from the cartridge with methanol (1 or $2 \mathrm{~mL}$ ).

The solid-phase extraction step above was modified for the analysis of oxysterols from brain, and the modified procedure was then subsequently used in all further studies. Therefore, for brain samples (and for reference compounds) the GP reaction mixture $(3 \mathrm{~mL}$ $70 \%$ methanol) after overnight incubation was directly applied to a Sep-Pak $C_{18}$ bed $(1 \mathrm{~cm} \times 0.8 \mathrm{~cm}$ in a glass column) followed by $1 \mathrm{~mL}$ of $70 \%$ methanol and $1 \mathrm{~mL}$ of $35 \%$ methanol. The combined effluent (now $5 \mathrm{~mL}$ ) was diluted with $4 \mathrm{~mL}$ of water. The resulting mixture (now $9 \mathrm{~mL}$ in 35\% methanol) was again applied to the column followed by a wash with $1 \mathrm{~mL}$ of $17 \%$ methanol. To the combined effluent $9 \mathrm{~mL}$ of water was added. The sample was then in $19 \mathrm{~mL}$ of about $17.5 \%$ methanol. This was again applied to the column followed by a wash with $10 \mathrm{~mL}$ of $10 \%$ methanol. Now all the GP derivatives are extracted by the column. They were then eluted with two $1 \mathrm{~mL}$ portions of methanol followed by 
Table 1. (Continued)

\begin{tabular}{cllll}
\hline Name & Abbreviation & Oxidation product & Mass of GP & Cmpd (MS/MS Fig $\left.{ }^{4}\right)$ \\
\hline \hline$\left[19,19,19-{ }^{2} \mathrm{H}_{3}\right]$ testosterone ${ }^{3}$ & $\begin{array}{l}{\left[19,19,19-{ }^{2} \mathrm{H}_{3}\right] \mathrm{A}^{4}-} \\
17 \beta-\text { ol-3-one }\end{array}$ & $\begin{array}{l}{\left[19,19,19-{ }^{2} \mathrm{H}_{3}\right] \mathrm{A}^{4}-17 \beta-} \\
\text { ol-3-one }\end{array}$ & 425.30 & XXVII \\
& & & \\
\hline
\end{tabular}

1. mono-GP hydrazone

2. bis-GP hydrazone

3. not treated with cholesterol oxidase

4. MS/MS Figure number, $\mathrm{S}$ refers to supplementary material

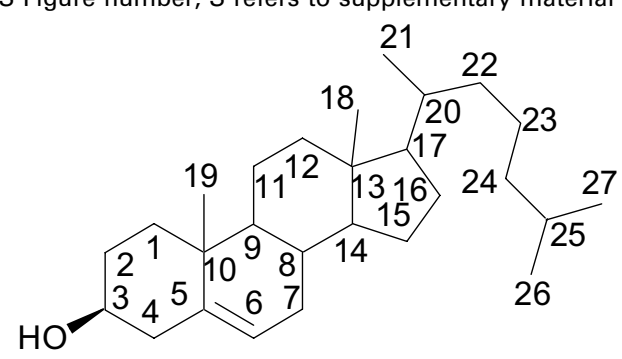

cholesterol skeleton $C^{5}-3 \beta-o l$

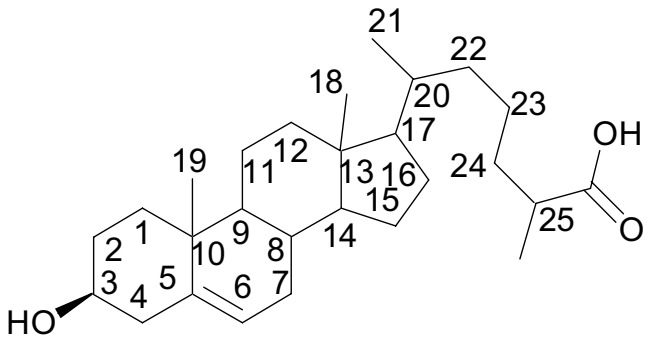

$3 \beta$-hydroxycholest-5-en-27-oic acid skeleton $C A^{5}-3 \beta$-ol

$1 \mathrm{~mL}$ of chloroform/methanol, 1:1 (vol/vol). The three fractions were analyzed separately by ES mass spectrometry. The GP derivatives were found predominantly in the second $\mathrm{mL}$ of methanol and the results of the analysis of this fraction are described below.

The derivatization protocol has been applied to mixtures of oxosteroids on the $\mu$ g-ng level and is suitable for the low level (pg) derivatization of neutral steroids extracted from tissue $[36,37]$.

\section{Extraction of Oxysterols from Brain}

In brief, oxysterols were extracted from $100 \mathrm{mg}$ of rat brain as follows: $100 \mathrm{mg}$ of brain was homogenized in ethanol $(1 \mathrm{~mL})$, the ethanol extract was centrifuged and the supernatant retained. The precipitate was ultrasonicated in $1 \mathrm{~mL}$ of methanol/dichloromethane (1:1, vol/ vol), centrifuged and the supernatant added to that retained previously. The combined supernatants were dried and redissolved in $2 \mathrm{~mL}$ of methanol/dichloromethane/water $(7: 2: 1, \mathrm{vol} / \mathrm{vol})$. This solution was added to a Lipidex DEAP (diethylaminohydroxypropyl Sephadex LH-20, PerkinElmer, Beaconsfield, Bucks,

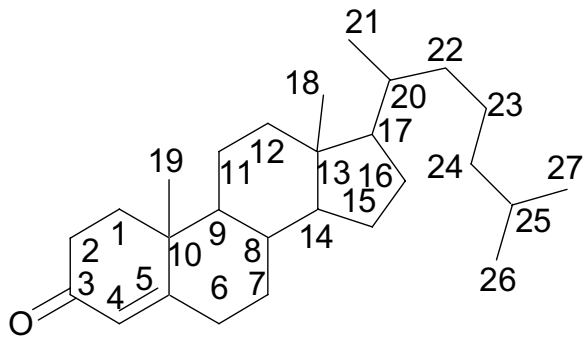

cholest-4-en-3-one skeleton $C^{4}$-3-one

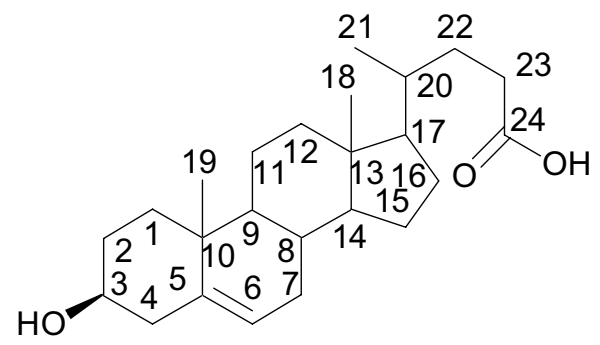

3ß-hydroxychol-5-en-24-oic acid skeleton $\mathrm{BA}^{5}-3 \beta$-ol

UK) anion-exchange column in its acetate form [50] $(7 \times$ $0.4 \mathrm{~cm}$ ) prepared in methanol/dichloromethane/water (7:2:1, vol/vol). The column was washed with $2 \mathrm{~mL}$ of the same solvent, followed by $1 \mathrm{~mL}$ of methanol/ dichloromethane/water (2:2:1, vol/vol), and the "flowthrough" and "wash" combined, dried, and redissolved in $2 \mathrm{~mL}$ of hexane/dichloromethane (2:8, vol/vol). This "neutral fraction" was then applied to a Unisil column $(8 \times 0.8 \mathrm{~cm}, 200-325$ mesh, activated silicic acid, Clarkson Chromatography Products, Inc., South Williamsport, PA) prepared in hexane, and washed with $20 \mathrm{~mL}$ of hexane/dichloromethane (2:8, vol/vol) before sample application. Following sample application the column was washed with $80 \mathrm{~mL}$ of hexane/dichloromethane $(2: 8, \mathrm{vol} / \mathrm{vol})$, and eluted with $10 \mathrm{~mL}$ of ethylacetate. The eluate was dried and redissolved in 50 $\mu \mathrm{L}$ isopropanol, and used as described above.

\section{Mass Spectrometry}

ES mass and collision-induced dissociation (CID) spectra were recorded on Q-TOF Ultima API and Q-TOF Global quadrupole (Q)-orthogonal accelera- 
tion (OA) time-of-flight (TOF) instruments, and also on a Quattro Micro tandem quadruple instrument (all Micromass/Waters, Manchester, UK). Each instrument was fitted with a Z-spray nano-ES interface and samples were electrosprayed from metal-coated borosilicate capillaries (Proxeon Biosystems A/S, Odense, Denmark or New Objective, Woburn MA) loaded with 1-5 $\mu \mathrm{L}$ of oxosteroid GP hydrazone (1 $\mathrm{ng} / \mu \mathrm{L})$ in methanol. On the Q-TOF and tandem quadrupole instruments the capillary voltages used were $\sim 1.75$ and $1.2 \mathrm{kV}$, respectively. On the Q-TOF instruments the cone-voltage was $100 \mathrm{~V}$ and the RF lens voltage varied between 40 and $200 \mathrm{~V}$. On the tandem quadrupole the cone-voltage was varied between 30 and $60 \mathrm{~V}$, with the RF lens voltage at $0.2 \mathrm{~V}$. With each instrument a counter current of dry nitrogen was used to aid solvent evaporation (cone gas, $40-100 \mathrm{~L} / \mathrm{h}$ ). With the Q-TOF instruments the collision cell located between the quadrupole and TOF sections of the instrument was loaded with argon giving a pressure reading on the near-by "analyzer" Penning gauge of $\sim 5 \times 10^{-5}$ mbar. Gas was maintained in the collision cell when recording both mass and MS/MS spectra. For the recording of mass spectra the potential offset on the collision cell was $10 \mathrm{~V}$ (collision energy $10 \mathrm{eV}$ for singly-charged ions). This was varied between 10 and $50 \mathrm{~V}$ for the recording of MS/MS spectra. The optimum value was established to be $35 \mathrm{~V}$ for singly charged ions, while $17.5 \mathrm{~V}$ (35 $\mathrm{eV})$ was used for doubly charged ions. The TOF analyzer could be operated with either "V" $(10,000$ resolution, full width at half maximum height definition, FWHM) or "W" (17,500 resolution, FWHM) optics. Most spectra were recorded with "W" optics. When MS/MS spectra were recorded on the tandem quadrupole, the hexapole collision cell was loaded with Ar gas so as to give a pressure reading of $3 \times$ $10^{-3}$ mbar on the gas-cell Pirani gauge. The collision energy was varied in the range of $10-50 \mathrm{eV}$. The tandem quadrupole instrument has the additional capacity to record both precursor ion and neutral loss scans.

\section{LC-MS and LC-MS/MS}

LC-MS and LC-MS/MS chromatograms were recorded on the Q-TOF Global mass spectrometer interfaced to a Cap-LC low flow-rate chromatography system (Micromass/Waters). Separation was achieved on a $\mathrm{C}_{18}$ capillary column (PepMap $\mathrm{C}_{18}$ column $180 \mu \mathrm{m} \times 150 \mathrm{~mm}, 3 \mu \mathrm{m}, 100$ A, Dionex, Camberley, Surrey, UK), at a flow-rate set to 1 $\mu \mathrm{L} / \mathrm{min}$. Mobile phase A was $50 \%$ methanol, $0.1 \%$ formic acid, and mobile phase B consisted of $95 \%$ methanol, $0.1 \%$ formic acid. Gradient elution was performed starting at $5 \% \mathrm{~B}$ and rising to $60 \%$ B over the first $10 \mathrm{~min}$, increasing to $80 \% \mathrm{~B}$ during the next $5 \mathrm{~min}$, and staying at $80 \% \mathrm{~B}$ for a final $10 \mathrm{~min}$, before returning to $5 \% \mathrm{~B}$.

\section{Results}

\section{Oxidation of $3 \beta-H y d r o x y-\Delta^{5}$ Sterols to 3-Oxo- $\Delta^{4}$ Sterols}

It was found necessary to modify the original procedure of Brooks et al. [47] for the oxidation of $3 \beta$-hydroxy- $\Delta^{5}$ steroids, so as to make it compatible with the ES-MS analysis of oxosterols and their GP hydrazones. Isopropanol is a good solvent for oxysterols, and cholesterol oxidase was found to be still active when a solution of oxysterol(s) in $50 \mu \mathrm{L}$ of isopropanol was added to $1 \mathrm{~mL}$ of the enzyme in $50 \mathrm{mM}$ phosphate buffer at $\mathrm{pH}$ 7. The use of detergent to solubilize the enzyme and the oxysterols was avoided, as it was found be difficult to completely remove the detergent from the oxidation products. After a suitable incubation period, our normal procedure was then to add methanol, GP hydrazine and glacial acetic acid so as to obtain the derivative directly without isolation of the ketone intermediate. In preliminary experiments, however, the efficiency of the oxidation reaction was evaluated by analysis of the ketone formed before derivatization. This was achieved by terminating the oxidation reaction by addition of methanol to the reaction solution and extracting the oxosterols on a $\mathrm{C}_{18}$ column using a recycling method. By using the "recycling" method of solid-phase extraction it was possible to apply the oxosterols to the $\mathrm{C}_{18}$ column in a solution of high methanol content $(50 \%$ methanol). This was desirable to ensure that the oxosterols were dissolved-in, rather than dispersed-in, solution. The initial flow-through from the $C_{18}$ column was collected and diluted with water so as to decrease its elutropic strength, the diluted flow-through was then recycled through the column. Any oxosterols not retained by the column following their initial application were subsequently extracted by the column on reapplication of the diluted flow-through. To monitor the efficiency of the purification of oxosterols the entire procedure was carried out using ${ }^{14} \mathrm{C}$-labeled cholesterol. Radioactivity was found to be exclusively retained on the column, and then completely eluted with methanol.

The activity of the enzyme under the solution conditions employed for the oxidation reaction was evaluated with the use of $3 \beta$-hydroxycholest-5-en-27-oic and $3 \beta$-hydroxychol-5-en-24-oic acids. Both of these acids will give $[\mathrm{M}-\mathrm{H}]^{-}$ions upon negative-ion ES ionization, and hence their oxidation reactions can be monitored by the decrease in $[\mathrm{M}-\mathrm{H}]^{-}$ion currents and the complementary increase in ion current of the oxidation products. Under the reaction conditions employed the oxidation reactions were found to proceed to completion.

The choice of reaction time may have to be determined by the exact aim of the analysis. Compounds having additional substituents in the A-ring and steroids with no $\left(C_{19}\right)$ or a short $\left(C_{21}\right)$ side-chain react much slower than cholesterol (see reference [48] for a 
table of reaction rates for different steroids). We investigated the effect of an extended reaction time on the oxidation of cholesterol and found that minor products with additional oxygens were formed when the oxidation time exceeded $5 \mathrm{~h}$, indicating that the cholest-4-en3-one underwent further oxidation.

Although not the focus of the current study, $5 \alpha$ steroids with a $3 \beta$-hydroxy group can be oxidized to 3 -oxo- $5 \alpha$-steroids. Using the above procedure lathosterol (3 3 -hydroxy- $5 \alpha$-cholest-7-ene, $5 \alpha-C^{7}-3 \beta$-ol) was successfully oxidized to its 3-oxo equivalent $\left(5 \alpha-C^{7}-3-\right.$ one), as were a number of other $3 \beta$-hydroxy- $5 \alpha$-steroids.

\section{Derivatization of Oxosterols}

The derivatization of oxosterols to GP hydrazones was carried out essentially as described previously [38, 39]. However, it was found to be necessary to modify the reaction conditions for the derivatization of oxosterols with a labile 7-hydroxy- $\Delta^{4}$-3-oxo structure which otherwise underwent partial elimination of water with formation of a dienone. This was achieved by allowing the reaction to proceed at room temperature over night. Under these milder conditions, the efficiency of the derivatization reaction was monitored using 3-oxocholest-4-en-27-oic ( $\mathrm{CA}^{4}$-3-one) and 3-oxochol-4-en-24-oic (BA ${ }^{4}$-3-one) acids, which in their underivatized forms give $[\mathrm{M}-\mathrm{H}]^{-}$ion signals in ES spectra. After $12 \mathrm{~h}$, the signals for the underivatized acids were found to fall to zero. It should be noted that for the majority of studies, the derivatization reaction was carried out directly on the products of the cholesterol oxidase reaction, without any further purification or extraction.

Oxosteroids with structures other than 3-oxo- $\Delta^{4}$ were successfully derivatized with the GP reagent. For example, $5 \alpha$-cholestan-3-one ( $5 \alpha$-C-3-one), $17 \alpha$-acetoxy$5 \alpha$-androstan-3-one ( $5 \alpha$-A-17 $\alpha$-acetoxy-3-one), $20 \beta, 21$ dihydroxy-5 $\beta$-pregnan-3-one (5 $\beta$-P-20 $\beta, 21$-diol-3-one) were converted to their 3-GP hydrazones; while $3 \beta$ hydroxy- $5 \alpha$-cholestan-7-one ( $5 \alpha$-C-3 $\beta$-ol-7-one), 7-oxocholesterol (C $C^{5}-3 \beta$-ol-7-one), $3 \beta$-hydroxy- $5 \alpha$-cholest$8(14)$-en-15-one $\left(5 \alpha-\mathrm{C}^{8(14)}-3 \beta\right.$-ol-15-one), a kind gift from G. Schroepfer, and $3 \beta, 17 \beta$-dihydroxy-androst-5en-16-one $\left(A^{5}-3 \beta, 17 \beta\right.$-16-one) were converted to $7-G P$, 7-GP- $\Delta^{5}$, 15-GP-D ${ }^{8(14)}$, and 16-GP- $\Delta^{5}$ hydrazones, respectively. Additionally, cholesta-4,6-dien-3-one $\left(C^{4,6}\right.$ 3-one) was successfully converted to a 3-GP hydrazone, and the plant sterol campesterol $\left(\mathrm{C}^{5}-24 \alpha\right.$-methyl-3 $\beta$-ol $)$ was successfully oxidized and derivatized to a 3-oxo$\Delta^{4}$-3-GP hydrazone. Steroids containing two oxo groups were converted to mono- and to a minor extent to bis-GP derivatives. Depending on the position of the second oxo group (i.e., the one not at C-3), the formation of the bis-GP derivative was sometimes more pronounced (e.g., 3,17-, 3,6- and 3,22-diones). Further studies are required to establish the reaction rates for steroids with multiple oxo groups.

\section{Tandem Mass Spectrometry of Oxosterol GP Hydrazones}

Instrumental effects. Three tandem mass spectrometers were used in this study each fitted with a nano-ES source. Two of the instruments were of Q-TOF type, the third was a tandem quadrupole. At a defined collision energy, the three instruments gave similar but not identical spectra. Some instrumental effects were noted, in particular the transmission of low-mass fragmentsions ( $<200 \mathrm{Da}$ ) was found to be greater on the tandem quadrupole than on the Q-TOF instruments. This is illustrated in Figure 1, which shows 35 eV CID spectra of $\mathrm{C}^{4}$-24-ol-3-one GP hydrazone (VI) recorded on the tandem quadrupole (1a), Q-TOF Ultima API (1b), and Q-TOF Global (1c) instruments. Note that in the spectrum recorded on the Q-TOF instruments (Figure $1 \mathrm{~b}$ and c) the $m / z$ ranges 50-121 and 122-390 have been magnified. The Q-TOF instruments also provide much higher product-ion resolution than the tandem quadrupole instrument. Using the Q-TOF instruments and employing " $\mathrm{W}$ " ion-optics, the product-ion resolution was of the order of 17,500 (FWHM), this in combination with the excellent stability of the instruments' $\mathrm{m} / \mathrm{z}$ range allowed the routine acquisition of accurate mass data ( $\pm 5-10 \mathrm{ppm}$ ).

In MS/MS spectra, 3-oxo- $\Delta^{4}$ sterol GP hydrazones give four main types of fragment ion: (i) those derived from the GP hydrazone group, (ii) those resulting from steroid ring and C-17 side-chain fragmentation and which contain the hydrazone group, (iii) those which are a result of the neutral loss of pyridine, carbon monoxide and water from the molecular ion, and (iv) those which correspond to small hydrocarbon ions (Schemes 2 and 5). Conveniently, ions in groups (i)-(iii) predominantly fall within distinct $\mathrm{m} / \mathrm{z}$ ranges, i.e., (i) 50-121; (iia) 121-180; (iib) 180-390; and (iii) above 390, and despite differences in absolute ion transmission between the instruments, within defined $\mathrm{m} / \mathrm{z}$ ranges the instruments give normalized MS/MS spectra which are quite similar, and allow a number of generalizations to be made concerning the low-energy CID of oxosterol GP hydrazones.

Group (i) fragment ions: GP hydrazone fragment ions. In all of the MS/MS spectra of the 3-oxo- $\Delta^{4}$ sterols studied a series of fragment ions characteristic of the GP hydrazone group is observed at $\mathrm{m} / \mathrm{z} 80.05,94.07,109.08,120.05$ and 137.07. High-resolution accurate mass data shows that these ions have the compositions $\mathrm{C}_{5} \mathrm{H}_{6} \mathrm{~N}\left(\sigma_{1}+\mathrm{H}\right)$, $\mathrm{C}_{5} \mathrm{H}_{5} \mathrm{NCH}_{3}\left(\sigma_{2}+\mathrm{H}\right), \mathrm{C}_{5} \mathrm{H}_{5} \mathrm{NCH}_{2} \mathrm{NH}_{2}\left(\sigma_{4}+\mathrm{H}-\mathrm{CO}\right)$, $\mathrm{C}_{5} \mathrm{H}_{5} \mathrm{NCHCO}\left(\sigma_{3}-\mathrm{H}\right)$, and $\mathrm{C}_{5} \mathrm{H}_{5} \mathrm{NCH}_{2} \mathrm{CONH}_{2}\left(\sigma_{4}+\mathrm{H}\right)$, respectively (Scheme 2). The peaks at 109 and 120 are in fact doublets consisting of $\mathrm{C}_{5} \mathrm{H}_{5} \mathrm{NCH}_{2} \mathrm{NH}_{2} / \mathrm{C}_{8} \mathrm{H}_{13}$ $(109.08 / 109.10)$ and $\mathrm{C}_{5} \mathrm{H}_{5} \mathrm{NCHCO} / \mathrm{C}_{8} \mathrm{H}_{10} \mathrm{~N}$ (120.05/ 120.08), respectively, which are easily resolved on the $\mathrm{Q}-\mathrm{TOF}$ instrument operated in the " $\mathrm{W}^{\prime}$-mode. The fragment-ion at $\mathrm{m} / \mathrm{z} 80.05$, abundant in the CID spectra re- 

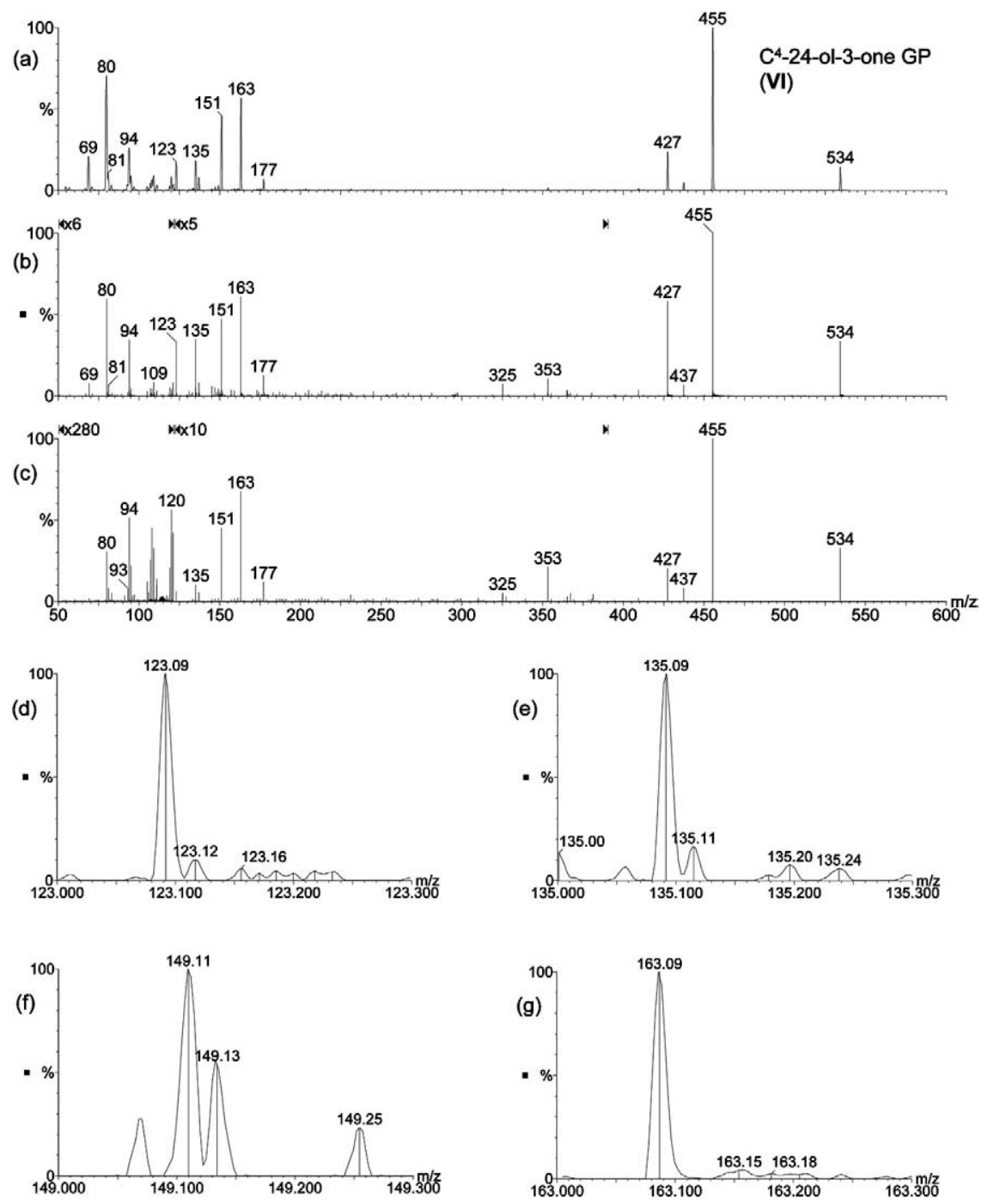

Figure 1. MS/MS spectra of the $[\mathrm{M}]^{+}$ion of $\mathrm{C}^{4}-24-01-3-o n e$ GP hydrazone (VI, $m / z$ 534). Spectra recorded on (a) tandem quadruple; (b) Q-TOF Ultima API, "W-mode"; (c) Q-TOF Global, "W-mode". Collision energy $35 \mathrm{eV}$. Expanded views of the peaks at $m / z 123$ (d); 135 (e), 149 (f), and $163(\mathrm{~g})$ from spectrum (c). In the spectra presented in (a), (b), and (c) the ratio of fragment ions 123.09:135.09:149.11 are 9:10:2, 9:10:1 and 6:10:2, respectively. In (b) and (c), regions $m / z$ 50-121 and 122-390 have been magnified by factors of 6 and 5 , and 280 and 10, respectively. The y-axis represents relative abundance. $1-5 \mu \mathrm{L}$ of sample $(1 \mathrm{ng} / \mu \mathrm{L})$ was loaded into the nano-ES capillary, and about $1 \mu \mathrm{L}$ consumed for the acquisition.

corded on the tandem quadrupole instrument, is an ideal target ion for precursor-ion scanning.

\section{3-Oxo- $\Delta^{4}$ Sterols: Compounds V-XVI (see Table 1)}

Group (iia) fragment ions: Steroid skeleton fragment ions. 3-Oxo- $\Delta^{4}$ sterol GP hydrazones undergo fragmentation in the steroid-ring in an identical fashion to other 3-oxo- $\Delta^{4}$ steroid GP hydrazones [38]. In the absence of additional substituents on the $A B C$ rings, 3-oxo- $\Delta^{4}$ steroid GP hydrazones give two major series of fragment ions at $m / z 151.09\left({ }^{*} b_{1}-12\right), 163.09\left({ }^{*} b_{2}-C_{2} /\right.$ $\left.{ }^{*} \mathrm{~b}_{3}-\mathrm{C}_{2} \mathrm{H}_{4}\right)$ and $177.10\left({ }^{*} \mathrm{~b}_{2}\right)$; and at $123.09\left({ }^{*} \mathrm{~b}_{1}-12\right), 135.09$ $\left({ }^{*} \mathrm{~b}_{2}-\mathrm{CH}_{2} /{ }^{*} \mathrm{~b}_{3}-\mathrm{C}_{2} \mathrm{H}_{4}\right)$ and $149.11\left({ }^{*} \mathrm{~b}_{2}\right)$ (Figures 1 and 2) $[38,39]$. The ${ }^{*} \mathrm{~b}$ ion-series corresponds to B-ring frag- ment ions which have additionally lost the pyridine ring of the GP hydrazone group, while the " $\mathrm{b}$ ion-series corresponds to B-ring fragments where the pyridine ring and $\mathrm{CO}$ groups have been lost (Scheme 2) [38, 39]. Griffiths et al. have shown that the ${ }^{*} b_{1}-12,{ }^{*} b_{2}-C_{2} H_{2}{ }^{*} b_{3}-$ $\mathrm{C}_{2} \mathrm{H}_{4}$ and ${ }^{*} b_{2}$ ions are formed via a $[\mathrm{M}-79]^{+}$intermediate (which corresponds to the molecular-ion having lost the pyridine ring), while the ${ }^{\#} b_{1}-12,{ }^{*} b_{2}-C_{2} /{ }^{*} b_{3}$ $\mathrm{C}_{2} \mathrm{H}_{4}$ and ${ }^{\#} \mathrm{~b}_{2}$ ions are formed via a [M-79-28] ${ }^{+}$intermediate (Scheme 2) [38, 39]. Detailed studies using heavyisotope labels have shown the ${ }^{*} \mathrm{~b}_{1}-12$ and ${ }^{*} \mathrm{~b}_{1}-12$ ions to contain the A-ring plus C-19, but minus C-5; and the ${ }^{*} \mathrm{~b}_{2}$ and ${ }^{\#} \mathrm{~b}_{2}$ ions to contain the A-ring plus $\mathrm{C}-19$ and C-6 (Scheme 3) $[38,39]$. The hypothesized ${ }^{*} \mathrm{~b}_{2}-\mathrm{CH}_{2}$ and ${ }^{\#} \mathrm{~b}_{2}-\mathrm{CH}_{2}$ fragments may more accurately be described as 

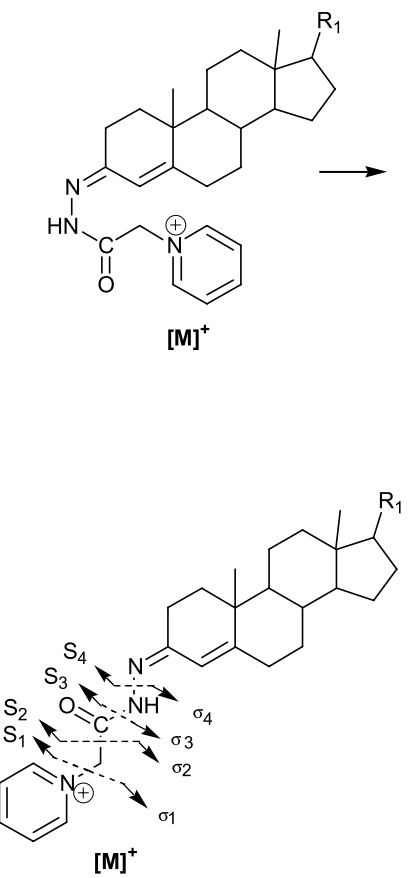

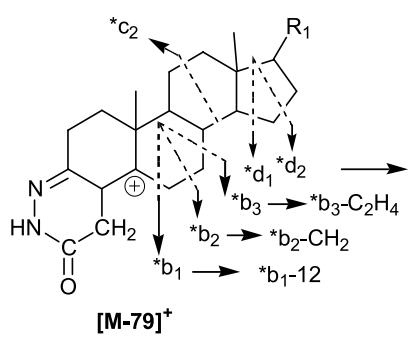

$\mathrm{S}_{1}$

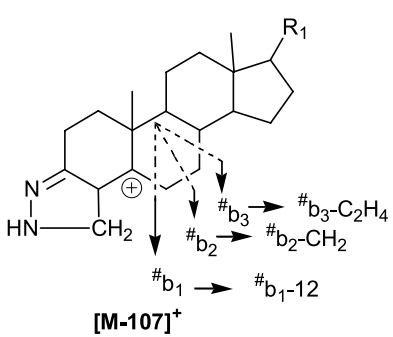

$\mathrm{S}_{1}-28$

Scheme 2. Fragmentation pattern of 3-oxo- $\Delta^{4}$ steroid 3-GP hydrazones.

${ }^{*} \mathrm{~b}_{2}-\mathrm{CH}_{3}-\mathrm{H}+2 \mathrm{H}$ and ${ }^{*} \mathrm{~b}_{2}-\mathrm{CH}_{3}-\mathrm{H}+2 \mathrm{H}$ ions. These ions are suggested to contain the A-ring and C-6, but C-19 has been lost and replaced by an $\mathrm{H}$-atom from $\mathrm{C}-7$ or the CD-rings, additionally the $\beta-\mathrm{H}$ on $\mathrm{C}-6$ has been replaced by an $\mathrm{H}$-atom from $\mathrm{C}-7$ or the $\mathrm{CD}$-rings [49]. The ${ }^{*} \mathrm{~b}_{3}-\mathrm{C}_{2} \mathrm{H}_{4}$ and ${ }^{*} \mathrm{~b}_{3}-\mathrm{C}_{2} \mathrm{H}_{4}$ ions contain the A-ring plus C- 6 and C-7, but C-19 and C-10 have been lost as has a $\mathrm{H}$-atom, probably the $\beta$-H from C-6 [52]. In 3-oxo- $\Delta^{4} \mathrm{GP}$ hydrazones containing no further $\mathrm{A}$ or $\mathrm{B}$ ring substituents the ${ }^{*} \mathrm{~b}_{3}-\mathrm{C}_{2} \mathrm{H}_{4}$ and ${ }^{*} \mathrm{~b}_{2}-\mathrm{CH}_{3}-\mathrm{H}+2 \mathrm{H}$ ions have identical elemental formula, as have the ${ }^{\#} \mathrm{~b}_{3}-\mathrm{C}_{2} \mathrm{H}_{4}$ and ${ }^{\#} \mathrm{~b}_{2}$ $\mathrm{CH}_{3}-\mathrm{H}+2 \mathrm{H}$ ions [53]. Supporting evidence for the structures of the B-ring fragment ions described above (Scheme 3) has been obtained in the current study where the ${ }^{*} b_{1}-12$ and ${ }^{*} b_{1}-12 ;{ }^{*} b_{2}-C_{2} /{ }^{*} b_{3}-C_{2} H_{4}$ and ${ }^{*} \mathrm{~b}_{2}-\mathrm{CH}_{2} /{ }^{\#} \mathrm{~b}_{3}-\mathrm{C}_{2} \mathrm{H}_{4}$; and ${ }^{*} \mathrm{~b}_{2}$ and ${ }^{*} \mathrm{~b}_{2}$ fragment-ions from $\left[2,2,4,23-{ }^{2} \mathrm{H}_{4}\right] \mathrm{BA}^{4}-3$-one and $\left[2,2,4,23-{ }^{2} \mathrm{H}_{4}\right] \mathrm{BA}^{4}$-3-one-24oylglycine GP hydrazones (XXIII and XXIV respectively) were each found to be +3 Da heavier than the equivalent ions from the monoisotopomers see Figure S-3 in the Supplementary Material section (which can be found in the electronic version of this article.). It should be noted that the peaks at $m / z 123,135,149$, and 163 consisted of doublets (Figure 1d-g). This is evident when spectra are recorded at high-resolution with the $\mathrm{Q}-\mathrm{TOF}$ instruments operated with " $\mathrm{W}$ " ion-optics. At $\mathrm{m} / \mathrm{z} 123.12,135.12,149.13$, and 163.15 peaks corresponding to $\mathrm{C}_{9} \mathrm{H}_{15}, \mathrm{C}_{10} \mathrm{H}_{15}, \mathrm{C}_{11} \mathrm{H}_{17}$ and $\mathrm{C}_{12} \mathrm{H}_{19}$ respectively, are resolved from those at $123.09\left({ }^{\#} b_{1}-12, C_{7} \mathrm{H}_{11} \mathrm{~N}_{2}\right)$, $135.09 \quad\left({ }^{*} \mathrm{~b}_{2}-\mathrm{CH}_{2} /{ }^{\#} \mathrm{~b}_{3}-\mathrm{C}_{2} \mathrm{H}_{4}, \mathrm{C}_{8} \mathrm{H}_{11} \mathrm{~N}_{2}\right), \quad 149.11$ (" $\mathrm{b}_{2}$, $\left.\mathrm{C}_{9} \mathrm{H}_{13} \mathrm{~N}_{2}\right)$, and $163.09\left({ }^{*} \mathrm{~b}_{2}-\mathrm{CH}_{2} /{ }^{*} \mathrm{~b}_{3}-\mathrm{C}_{2} \mathrm{H}_{4}, \mathrm{C}_{9} \mathrm{H}_{11} \mathrm{~N}_{2} \mathrm{O}\right)$.

Addition of a 7-hydroxy group to the steroid skeleton drastically alters the pattern of B-ring fragment ions for 3-oxo- $\Delta^{4}$ sterol GP hydrazones (Figure 2). Fragment ions at $m / z 135,149,163$, and 177 are attenuated in the spectra of 7-hydroxy-3-oxo- $\Delta^{4}$ steroid GP hydrazones, and accurate mass measurements at high-resolution confirm that it is the ${ }^{*} \mathrm{~b}_{2}-\mathrm{CH}_{2},{ }^{*} \mathrm{~b}_{2},{ }^{*} \mathrm{~b}_{2}-\mathrm{CH}_{2}$, and ${ }^{*} \mathrm{~b}_{2}$ components at these integer masses which are reduced in abundance. In the spectrum of a 7-hydroxy-3-oxo- $\Delta^{4}$ steroid GP hydrazone the ${ }^{*} b_{3}-C_{2} H_{4}$, and ${ }^{*} b_{3}-C_{2} H_{4}$ fragment ions are expected to be shifted to $\mathrm{m} / \mathrm{z} 151.09$ $\left(135.09+15.99, \mathrm{C}_{8} \mathrm{H}_{11} \mathrm{~N}_{2} \mathrm{O}\right)$ and $179.08(163.09+15.99$, $\mathrm{C}_{9} \mathrm{H}_{11} \mathrm{~N}_{2} \mathrm{O}_{2}$ ), respectively. Significantly, in the CID spectrum of $\mathrm{C}^{4}-7 \beta$-ol-3-one GP hydrazone $(\mathbf{V})$ (Figure 2e) the abundance of ions at $\mathrm{m} / \mathrm{z} 151.09$ and 179.08, corresponding to ions of composition $\mathrm{C}_{8} \mathrm{H}_{11} \mathrm{~N}_{2} \mathrm{O}$ and $\mathrm{C}_{9} \mathrm{H}_{11} \mathrm{~N}_{2} \mathrm{O}_{2}$, are enhanced in comparison to CID spectra of $\mathrm{C}^{4}$-24-ol-3-one (VI) (Figure 2a and b), $\mathrm{C}^{4}$-25-ol-3-one (VII) (Figure 2c), and $\mathrm{C}^{4}$-27-ol-3-one (VIII) (Figure 2d). The elemental composition $\mathrm{C}_{8} \mathrm{H}_{11} \mathrm{~N}_{2} \mathrm{O}(\mathrm{m} / z$ 151.09) corresponds to $\mathrm{a}{ }^{*} \mathrm{~b}_{1}-12$ ion, $\mathrm{a}{ }^{*} \mathrm{~b}_{3}-\mathrm{C}_{2} \mathrm{H}_{4}$ ion and also a ${ }^{*} \mathrm{~b}_{2}-\mathrm{CH}_{3}-\mathrm{H}+\mathrm{H}+\mathrm{OH}$ ion in $\mathrm{C}^{4}-7 \beta$-ol-3-one GP hydrazone (V). The elemental composition $\mathrm{C}_{9} \mathrm{H}_{11} \mathrm{~N}_{2} \mathrm{O}_{2}(\mathrm{~m} / \mathrm{z}$ 179.08) corresponds to a ${ }^{*} b_{3}-\mathrm{C}_{2} \mathrm{H}_{4}$ ion or a ${ }^{*} \mathrm{~b}_{2}-\mathrm{CH}_{3}-\mathrm{H}+$ $\mathrm{H}+\mathrm{OH}$. It is not surprising that the intensity of the peaks corresponding to ${ }^{*} \boldsymbol{b}_{2}(\mathrm{~m} / \mathrm{z} 149.11)$ and ${ }^{*} \boldsymbol{b}_{2}(\mathrm{~m} / \mathrm{z}$ 177.10) are attenuated in the CID spectra of 7-hydroxy3-oxo- $\Delta^{4}$ steroid GP hydrazones, as dehydration in the B-ring would lead to the introduction of a double-bond between C-6 and C-7 and resonance stabilization of the positive-charge (Scheme 4). With the blocking of the ${ }^{*} b_{2}$ and ${ }^{*} b_{2}$ fragmentation channels, additional ion current could then be channelled through to the ${ }^{*} b_{1}-12(\mathrm{~m} / z$ 123.09) and ${ }^{*} b_{1}-12(m / z$ 151.09) fragments.

In the CID spectra of 7-hydroxy-3-oxo- $\Delta^{4}$ steroid GP hydrazones (e.g., Figure 2e) the fragment ion at $\mathrm{m} / \mathrm{z}$ 179.08 corresponds to ${ }^{*} \mathrm{~b}_{2}-\mathrm{CH}_{3}-\mathrm{H}+\mathrm{H}+\mathrm{OH}$ and to 

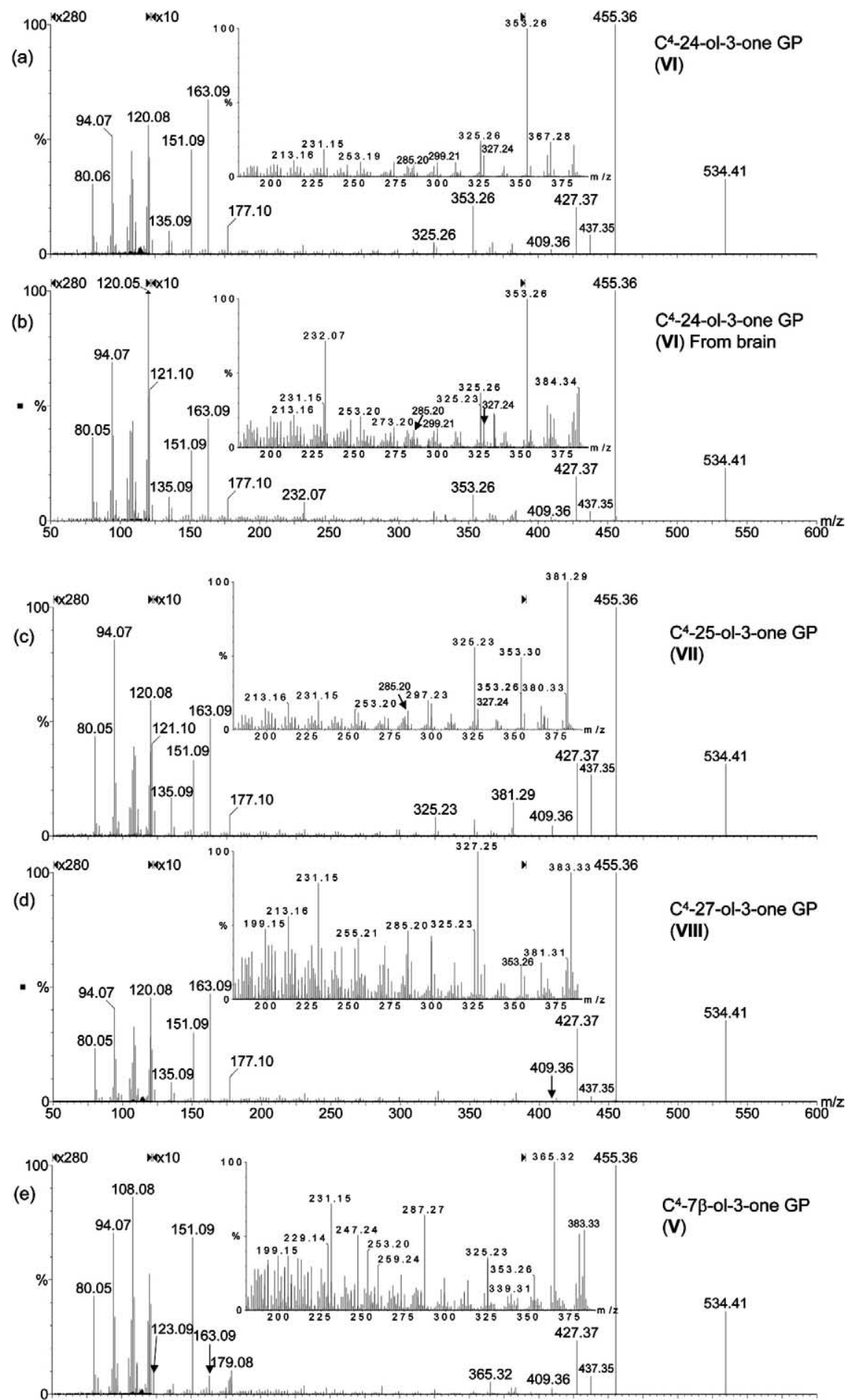

Figure 2. MS/MS spectra of the $[\mathrm{M}]^{+}$ion of GP hydrazones (a) $\mathrm{C}^{4}$-24-ol-3-one (VI, $\mathrm{m} / z$ 534.41); (b) $\mathrm{C}^{4}$-24-ol-3-one from brain (VI, $\mathrm{m} / \mathrm{z}$ 534.41); (c) $\mathrm{C}^{4}$-25-ol-3-one (VII, $\mathrm{m} / \mathrm{z}$ 534.41); (d) $\mathrm{C}^{4}$-27-ol-3-one (VIII $m / z$ 534.41); (e) $C^{4}-7 \beta$-ol-3-one (V, $m / z$ 534.41); (f) $C^{4}$-3,22-dione ( $\mathbf{X}, m / z$ 532.39). The spectra in (a)-(f) are of 3-GP hydrazones, that in $(\mathrm{g})$ is of the $[\mathrm{M}]^{2+}$ ion of $\mathrm{C}^{4}$-3,22-dione 3,22-bisGP hydrazone $(\mathbf{X I}, \mathrm{m} / \mathrm{z}$ 333.23). (h) Expanded views of the peaks at $m / z 325$ and 353 recorded at 17,500 (top panel) or 12,000 (central and bottom panel) resolution, FWHM definition. The upper panels in (h) show peaks from $\mathrm{C}^{4}$-24-ol-3-one GP (VI); the central panels in (h) show peaks from $\mathrm{C}^{4}$-25-ol-3-one GP (VII); and the bottom panels in (h) show peaks from $C^{4}$-27-ol-3-one GP (VIII). In the spectra presented in (a)-(g) the ratio of fragment ions 123.09:135.09:149.11 and 151.09:163.09:177.10 are 6:10:2 and 7:10:2 (a); 7:10:2 and 7:10:2 (b); 7:10:2 and 6:10:2 (c); 6:10:2 and 6:10:2 (d); 10:2:1 and 10:1:1 (e); 7:10:1 and 8:10:1 (f); 6:10:2 and 

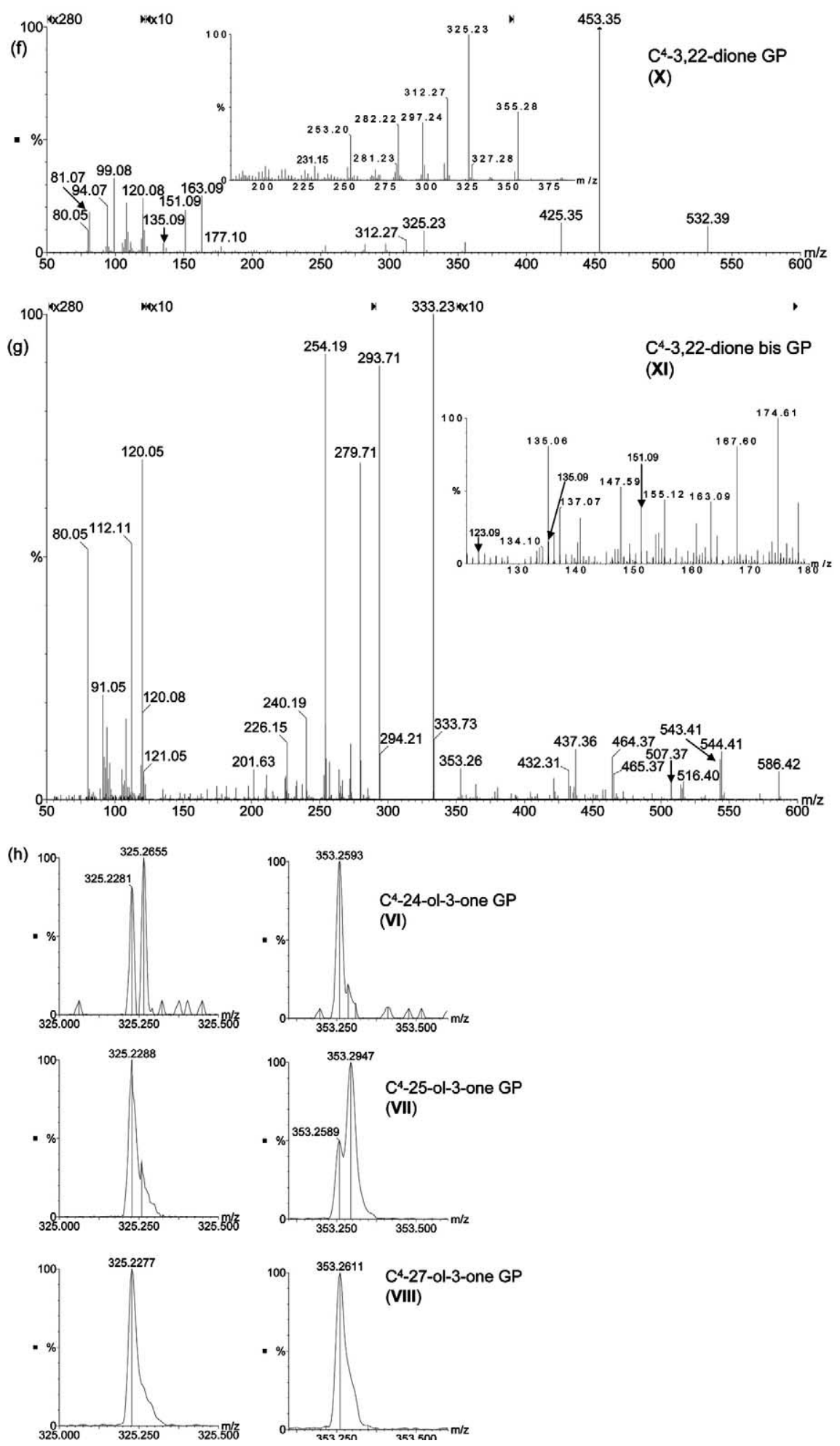

Figure 2 (continued). 10:10:2 (g). In (a)-(f) the $m / z$ regions 50-121 and 122-390 have been magnified by a factor of 280 and 10, respectively. In (g) the regions 50-121, 122-290, and 350-600 have been magnified by a factor of 280,10 , and 10 , respectively. The y-axis represents relative abundance. All spectra recorded on the Q-TOF Global instrument in "W-mode" at a collision energy $35 \mathrm{eV} .1-5 \mu \mathrm{L}$ of sample $[1 \mathrm{ng} / \mu \mathrm{L}$ for steroid standards and $10 \mu \mathrm{g}$ brain $/ \mu \mathrm{L}$ in (b)] was loaded into the nano-ES capillary, and about $1 \mu \mathrm{L}$ consumed for the acquisition. 


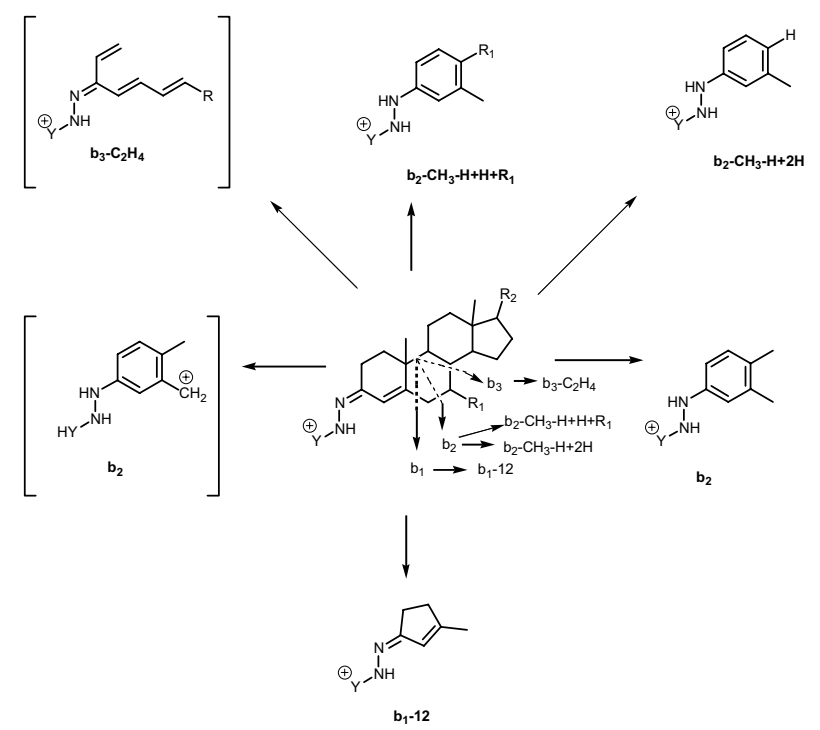

Scheme 3. Structures of b-type fragment ions. For simplicity the hydrazone has been drawn as a linear chain; alternatively the Y-group can be bound to $\mathrm{C}-4$ with charge located on the A-ring. In *b-type ions $\mathrm{Y}=\mathrm{COCH}_{2}$, in "b-type ions $\mathrm{Y}=\mathrm{CH}_{2}$. The structures in brackets are analogous to those suggested to correspond to fragment ions of protonated testosterone [52].

${ }^{*} \mathrm{~b}_{3}-\mathrm{C}_{2} \mathrm{H}_{4}$ ions. The ${ }^{*} \mathrm{~b}_{2}-\mathrm{CH}_{3}-\mathrm{H}+\mathrm{H}+\mathrm{OH}$ ion is analogous to the ${ }^{*} b_{2}-\mathrm{CH}_{3}-\mathrm{H}+2 \mathrm{H}$ ion normally observed at $m / z 163.09$ (Figure 2a-d), but where an OH-group rather than $\mathrm{H}$-atom is transferred from $\mathrm{C}-7$ to the ion (Scheme 3). The ${ }^{\#} \mathrm{~b}_{2}-\mathrm{CH}_{3}-\mathrm{H}+\mathrm{H}+\mathrm{OH}$ and ${ }^{*} \mathrm{~b}_{3}-\mathrm{C}_{2} \mathrm{H}_{4}$ ions have an identical elemental composition to $a{ }^{*} b_{1}-12$ ion and also contribute to the enhanced intensity of the ion at $m / z$ 151.09. This was evident when CID spectra were recorded of $[\mathrm{M}-107]^{+}$ions from 7-hydroxy-3oxo- $\Delta^{4}$ steroid GP hydrazones which can not fragment to give ${ }^{*} b-12$ ions, but were observed to give abundant fragment ions at $\mathrm{m} / \mathrm{z} 151.09$ corresponding to ${ }^{\#} \mathrm{~b}_{2}-\mathrm{CH}_{3}-\mathrm{H}$ $+\mathrm{H}+\mathrm{OH}$ and ${ }^{\#} \mathrm{~b}_{3}-\mathrm{C}_{2} \mathrm{H}_{4}$ ions (data not shown).

Group (iib) fragment ions: Minor (low abundance) ring and C-17 side-chain fragment ions. While the major cleavages in the steroid ring system occur in the B-ring and give abundant fragment ions, minor but important fragment ions are generated by cleavages in the $\mathrm{C}$ - and D-rings and in the C-17 side-chain giving ions of lower abundance. In the CID spectra of 3 -oxo- $\Delta^{4}$ sterol GP hydrazones ${ }^{*} \mathrm{C}_{2},{ }^{*} \mathrm{~d}_{1},{ }^{*} \mathrm{~d}_{2}{ }^{*} \mathrm{e}-\mathrm{H}$, and / or ${ }^{*} \mathrm{e}+\mathrm{H}$ fragment ions are consistently observed at $m / z \quad 231.15$ $\left(\mathrm{C}_{14} \mathrm{H}_{19} \mathrm{~N}_{2} \mathrm{O}\right)$, $285.20\left(\mathrm{C}_{18} \mathrm{H}_{25} \mathrm{~N}_{2} \mathrm{O}\right), 299.21\left(\mathrm{C}_{19} \mathrm{H}_{27} \mathrm{~N}_{2} \mathrm{O}\right)$, $325.23\left(\mathrm{C}_{21} \mathrm{H}_{29} \mathrm{~N}_{2} \mathrm{O}\right)$, and/or $327.24\left(\mathrm{C}_{21} \mathrm{H}_{31} \mathrm{~N}_{2} \mathrm{O}\right)$ (e.g., cmpds VI-VIII, Figure $2 \mathrm{a}-\mathrm{d}$, Scheme 2). Incorporation of a C-24 hydroxyl group results in the additional appearance of ${ }^{*} \mathrm{f}-\mathrm{H}$ and ${ }^{*} \mathrm{f}-\mathrm{H}$ fragment ions at $\mathrm{m} / \mathrm{z} 325.26$ $\left(\mathrm{C}_{22} \mathrm{H}_{33} \mathrm{~N}_{2}\right)$ and $353.26\left(\mathrm{C}_{23} \mathrm{H}_{33} \mathrm{~N}_{2} \mathrm{O}\right)(\mathrm{VI})$, (Figure $2 \mathrm{a}$ and b). These fragment ions are absent or much weaker in the spectra of $\mathrm{C}^{4}$-25-ol-3-one (VII) and $\mathrm{C}^{4}$-27-ol-3-one (VIII) (Figure 2c, d, and h). The presence of the 25hydroxyl group in $\mathrm{C}^{4}$-25-ol-3-one (VII) facilitates frag- mentation between C-23 and C-24 with the formation of comparatively abundant fragment ions at $353.30\left({ }^{\#} \mathrm{~h}-\mathrm{H}\right.$, $\mathrm{C}_{24} \mathrm{H}_{37} \mathrm{~N}_{2}$ ) and 381.29 ( ${ }^{*} \mathrm{~h}-\mathrm{H}, \mathrm{C}_{25} \mathrm{H}_{37} \mathrm{~N}_{2} \mathrm{O}$ ) (Figure $2 \mathrm{c}$ ). Incorporation of two hydroxyl groups in the C-17 side-chain as in $C^{4}$-20R,22R-diol-3-one GP hydrazone (XII) results in enhanced abundance of fragment ions at $299.25\left(\mathrm{C}_{20} \mathrm{H}_{31} \mathrm{~N}_{2}\right), 327.24\left(\mathrm{C}_{21} \mathrm{H}_{31} \mathrm{~N}_{2} \mathrm{O}\right)$, and 353.26 $\left(\mathrm{C}_{23} \mathrm{H}_{33} \mathrm{~N}_{2} \mathrm{O}\right)$ corresponding to ${ }^{\#} \mathrm{e}+\mathrm{H}$, ${ }^{*} \mathrm{e}+\mathrm{H}$ and ${ }^{*} \mathrm{f}+\mathrm{H}-$ $\mathrm{H}_{2} \mathrm{O}$ respectively (Figure $3 \mathrm{~b}$ ). Altering the steroid ring system by introduction of a labile 7-hydroxy group results in the formation of ${ }^{*} \mathrm{C}_{2}-\mathrm{H}_{2} \mathrm{O},{ }^{*} \mathrm{C}_{2}+2 \mathrm{H}-\mathrm{H}_{2} \mathrm{O}$, ${ }^{*} \mathrm{e}-\mathrm{H}-\mathrm{H}_{2} \mathrm{O}$, and / or ${ }^{*} \mathrm{e}+\mathrm{H}-\mathrm{H}_{2} \mathrm{O}$ fragment ions at $m / z$ $229.13\left(\mathrm{C}_{14} \mathrm{H}_{17} \mathrm{~N}_{2} \mathrm{O}\right), \quad 231.15\left(\mathrm{C}_{14} \mathrm{H}_{19} \mathrm{~N}_{2} \mathrm{O}\right), \quad 323.21$ $\left(\mathrm{C}_{21} \mathrm{H}_{27} \mathrm{~N}_{2} \mathrm{O}\right)$, and/or $325.23\left(\mathrm{C}_{21} \mathrm{H}_{29} \mathrm{~N}_{2} \mathrm{O}\right)$, respectively, (Scheme 4, Figure 2e, Figure 3a, and Supplementary Material Figure S-1). The combined presence of 7- and 25-hydroxyl groups on the $\mathrm{C}^{4}$-3-one template (XIII, $\mathrm{XIV)}$ results in enhanced intensity of a fragment ion at $341.22\left(\mathrm{C}_{21} \mathrm{H}_{29} \mathrm{~N}_{2} \mathrm{O}_{2}\right)$ corresponding to ${ }^{*} \mathrm{e}-\mathrm{H}$, particularly in spectra of the $7 \beta$ isomer (XIV). In contrast, the $7 \alpha$ isomer shows enhanced abundance of an ion at $203.15\left({ }^{\#} \mathrm{C}_{2}+2 \mathrm{H}-\mathrm{H}_{2} \mathrm{O}, \mathrm{C}_{13} \mathrm{H}_{19} \mathrm{~N}_{2}\right)$ and at $231.15\left({ }^{*} \mathrm{C}_{2}+\right.$ $2 \mathrm{H}-\mathrm{H}_{2} \mathrm{O}, \mathrm{C}_{14} \mathrm{H}_{19} \mathrm{~N}_{2} \mathrm{O}$ ) (XIII). Similarly, in spectra of $\mathrm{C}^{4}-7 \alpha, 27$-diol-3-one (XV), the fragment ions at 203.15 and 231.15 are comparatively abundant, but fragment ions are not observed at 341.22.

Group (iii) fragment ions: GP hydrazone neutral-loss fragment ions. Each of the 3-oxo- $\Delta^{4}$ sterol GP hydrazones investigated in the present study give $[\mathrm{M}-79]^{+}$and $[\mathrm{M}-107]^{+}$fragment ions which are formed by the neutral-loss of pyridine; and pyridine plus $\mathrm{CO}$, respectively (Scheme 2). Similar fragment ions were observed in the MS/MS spectra of other 3-oxo- $\Delta^{4}$ steroid GP hydrazones $[38,39]$. The added presence of hydroxyl groups on the cholest-4-en-3-one skeleton results in the additional formation of [M-79-(n18) ${ }^{+}$and [M-107-(n18) $]^{+}$ ions, where $\mathrm{n}$ is the number of additional hydroxyl groups. The relative intensities of these ions depend on the location of the hydroxyl groups. From the MS/MS

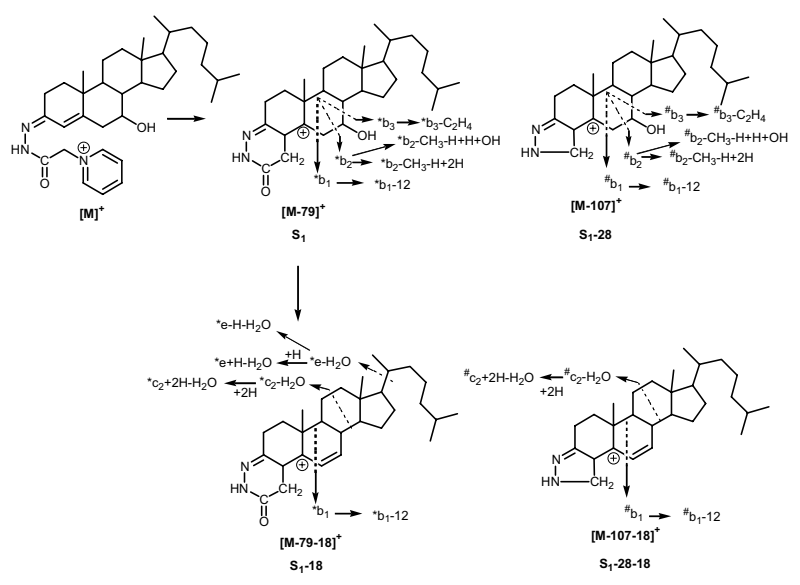

Scheme 4. Fragmentation pattern of 7-hydroxy-3-oxo- $\Delta^{4}$ steroid GP hydrazone. 


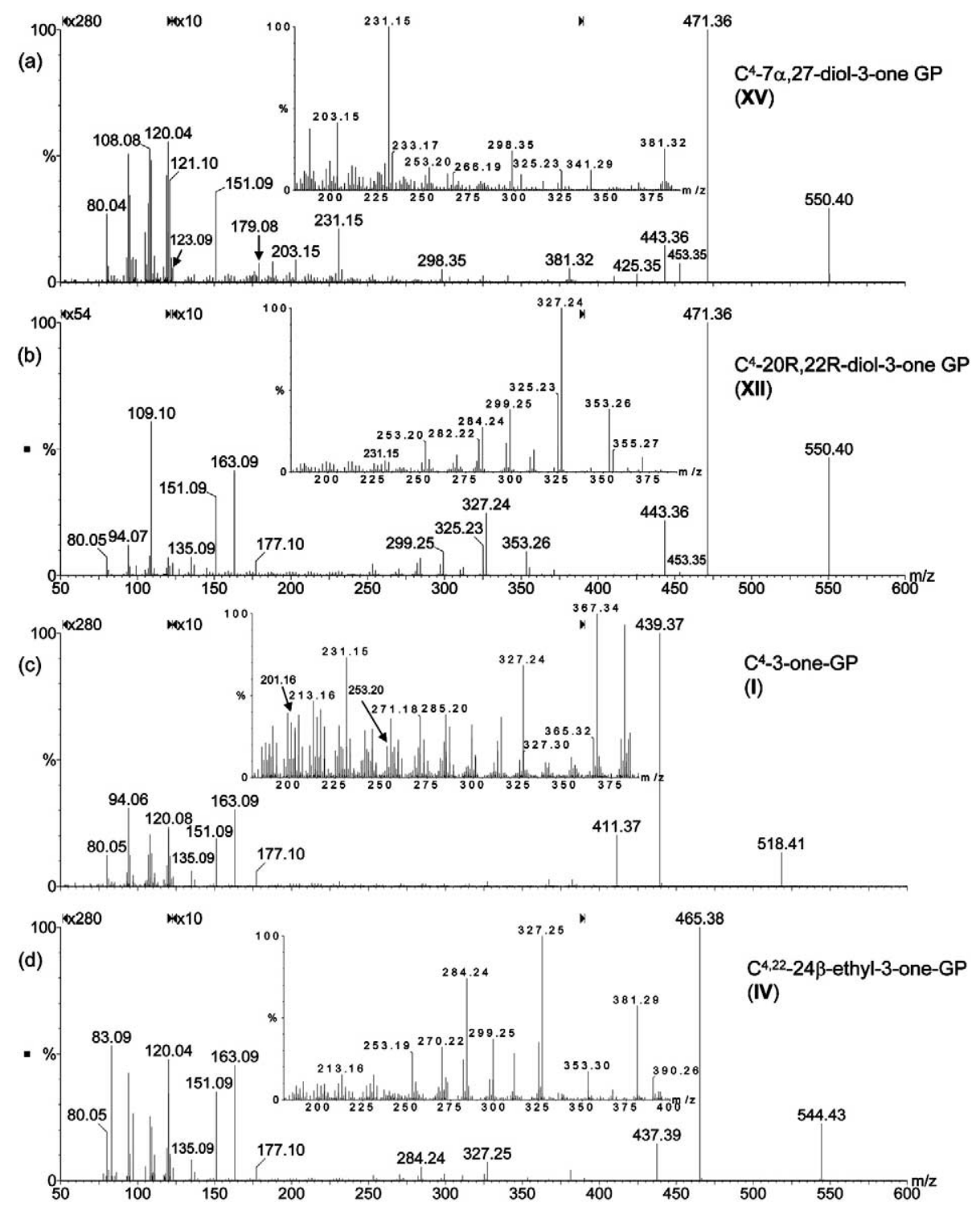

Figure 3. MS/MS spectra of the $[\mathrm{M}]^{+}$ion of GP hydrazones of (a) $\mathrm{C}^{4}-7 \alpha, 27$-diol-3-one $(\mathbf{X V}, \mathrm{m} / \mathrm{z}$ 550.40); (b) C $\mathrm{C}^{4}$-20R,22R-diol-3-one (XII, 550.40); (c) $\mathrm{C}^{4}$-3-one (I, $\mathrm{m} / \mathrm{z}$ 518.41); (d) $\mathrm{C}^{4,22}$-24 3 -ethyl-3-one (IV, $\mathrm{m} / \mathrm{z}$ 544.43). In the MS/MS spectra the ratio of fragment ions 123.09:135.09:149.11 and 151.09: 163.09:177.10 are 10:1:1 and 10:1:1 (a); 7:10:1 and 8:10:1 (b); 6:10:2 and 6:10:2 (c); 6:10:1 and 8:10:1 (d). In (a), (c), and (d) the $\mathrm{m} / z$ regions 50-121 and 122-390 have been magnified by a factor of 280 and 10, respectively, while in (b) by a factor of 54 and 10, respectively. The y-axis represents relative abundance. All spectra recorded on the Q-TOF Global instrument in "W-mode" at a collision energy $35 \mathrm{eV} .1-5 \mu \mathrm{L}$ of sample $(1 \mathrm{ng} / \mu \mathrm{L})$ was loaded into the nano-ES capillary, and about $1 \mu \mathrm{L}$ consumed for the acquisition.

spectra recorded of monohydroxy-3-oxo- $\Delta^{4}$ steroid GP hydrazones, the order of hydroxyl-group lability giving ${ }^{\mathrm{M}-79-18]^{+}}$and $[\mathrm{M}-107-18]^{+}$ions at 437.35 and 409.36 was determined to be $25-\mathrm{OH}>24-\mathrm{OH} \sim 7-\mathrm{OH}>27-\mathrm{OH}$ (Figure 2). This difference in the ease of dehydration between sterol isomers aids in their differentiation when not present in a mixture.

The hydroxyl groups at $20 \mathrm{R}$ and $22 \mathrm{R}$ are surprisingly stable, and in the CID spectrum of $C^{4}-20 R, 22 R$-diol-3one GP hydrazone (XII) the [M-79-(n18) ${ }^{+}$at 453.35 and 435.34; and [M-107-(n18) $]^{+}$ions at 425.35 and 407.34 are present at less than $2 \%$ of the intensity of the $[\mathrm{M}-79]^{+}$ ion (Figure 3b). In contrast, the hydroxyl group on C-25 is labile, this is evident in the CID spectra of $C^{4}-7 \beta, 25-$ diol-3-one (XIV) and $C^{4}-7 \alpha, 25$-diol-3-one (XIII) GP hydrazones (see Supplementary Material Figure S-1), where strong/medium intensity [M-79-18] ${ }^{+}$fragment ions are observed at $\mathrm{m} / \mathrm{z} 453.35$ (RA $55 \%, 20 \%$ ), as are weaker satellite peaks corresponding to [M-79- $(2 \times$ 18) $]^{+}$at $m / z 435.34$ (RA 5\%, 5\%), and [M-107-18] ${ }^{+}$at $m / z$ 425.35 (RA 5\%,5\%). Peaks are also observed at $\mathrm{m} / \mathrm{z}$ 407.34 from the $C^{4}-7,25$-diol-3-one isomers, corresponding to fragments $[\mathrm{M}-107-(2 \times 18)]^{+}$, but these are of low intensity (RA $2 \%, 2 \%$ ). In comparison, when the side- 
chain hydroxyl group is shifted from C-25 to C-27 as in $\mathrm{C}^{4}-7 \alpha, 27$-diol-3-one GP hydrazone (XV), [M-79-18 $]^{+}$ and $[\mathrm{M}-107-18]^{+}$ions are observed to give comparatively weak peaks $(\mathrm{m} / \mathrm{z} 453.35,5 \% ; \mathrm{m} / \mathrm{z} 425.35$, RA) (Figure 3a).

\section{Bile Acids, Compounds XVII-XXV: And 22- Oxocholesterols, Compounds X-XI (see Table 1)}

Cholest-5-en-27-oic acids are intermediates in the conversion of cholesterol to bile acids, and $3 \beta$-hydroxycholest-5-en-27-oic acid and its $7 \alpha$-hydroxylated product $3 \beta, 7 \alpha$-dihydroxycholest-5-en-27-oic acid are quantitatively dominating unconjugated bile acids in the human circulation [1,3]. After oxidation of these compounds with cholesterol oxidase and derivatization with GP hydrazine, the resulting 3-oxo- $\Delta^{4}$ acids undergo CID reactions to give fragment ions in accord with their structural features as discussed above (see Supplementary Material Figure S-2). For example, CID of $\left[16,16,17\right.$ (or 20),22,22,23,23- $\left.{ }^{2} \mathrm{H}_{7}\right] \mathrm{CA}^{4}$-3-one GP hydrazone (XVII) gives the " ${ }^{*}$-type fragment ions ${ }^{*} b_{1}-12(\mathrm{~m} / \mathrm{z}$ 123.09), " $\mathrm{b}_{2}-\mathrm{CH}_{2} /{ }^{n} \mathrm{~b}_{3}-\mathrm{C}_{2} \mathrm{H}_{4}(\mathrm{~m} / \mathrm{z} 135.09)$ and ${ }^{*} \mathrm{~b}_{2}(\mathrm{~m} / \mathrm{z}$ 149.11); and the ${ }^{*}$ b-type fragment ions ${ }^{*} b_{1}-12(\mathrm{~m} / z$ 151.09), ${ }^{*} \mathrm{~b}_{2}-\mathrm{CH}_{2} /{ }^{*} \mathrm{~b}_{3}-\mathrm{C}_{2} \mathrm{H}_{4}\left(\mathrm{~m} / \mathrm{z}\right.$ 163.09) and ${ }^{*} \mathrm{~b}_{2}(\mathrm{~m} / \mathrm{z}$ 177.10): while in CID spectra of 7-hydroxylated acids (and methyl esters), B-ring fragment ion peaks ${ }^{*} \mathrm{~b}_{2}-\mathrm{CH}_{2}$ $\left(m / z\right.$ 135.09), ${ }^{*} \boldsymbol{b}_{2}\left(m / z\right.$ 149.11), ${ }^{*} \boldsymbol{b}_{2}-\mathrm{CH}_{2}(m / z$ 163.09) and ${ }^{*} b_{2}(m / z 177.10)$ are attenuated. The presence of a 7-hydroxy group on the steroid skeleton results in enhanced intensity of the peak at $\mathrm{m} / \mathrm{z} 151.09$ corresponding to ${ }^{*} \mathrm{~b}_{3}-\mathrm{C}_{2} \mathrm{H}_{4}$ and ${ }^{*} \mathrm{~b}_{1}-12$, and also $\mathrm{m} / \mathrm{z} 179.08$ corresponding to ${ }^{*} \mathrm{~b}_{3}-\mathrm{C}_{2} \mathrm{H}_{4}$.

Ions of minor abundance but of structural importance are generated by cleavages in the C- and D-rings and the C-17 side-chain. In the CID spectrum of $[16,16,17$ (or 20),22,22,23,23- $\left.{ }^{2} \mathrm{H}_{7}\right] \mathrm{CA}^{4}-3$-one GP hydrazone (XVII) fragment ions characteristic of 3-oxo- $\Delta^{4}$ sterols are observed at $m / z 231.15,285.20,299.21$ corresponding to ${ }^{*} \mathrm{C}_{2},{ }^{*} \mathrm{~d}_{1}$, and ${ }^{*} \mathrm{~d}_{2}$ cleavages. A cluster of ions from $327.24\left(\mathrm{C}_{21} \mathrm{H}_{27} \mathrm{D}_{2} \mathrm{~N}_{2} \mathrm{O}\right.$, $\left.\left[{ }^{2} \mathrm{H}_{2}\right]^{*} \mathrm{e}-\mathrm{H}\right)$ to $330.26\left(\mathrm{C}_{21} \mathrm{H}_{28} \mathrm{D}_{3} \mathrm{~N}_{2} \mathrm{O},\left[{ }^{2} \mathrm{H}_{3}\right]^{*} \mathrm{e}+\mathrm{H}\right)$ is also seen corresponding to $*-\mathrm{H}$ and $* \mathrm{e}+\mathrm{H}$ fragment ion with differing degrees of deuteration. As was the case with the oxosterols discussed above, altering the steroid ring system by introduction of a labile 7-hydroxy group results in the formation of ${ }^{*} \mathrm{C}_{2}-\mathrm{H}_{2} \mathrm{O}$, and ${ }^{*} \mathrm{C}_{2}+2 \mathrm{H}-\mathrm{H}_{2} \mathrm{O}$, fragment ions at $\mathrm{m} / \mathrm{z} 229.13$, and 231.15; and a cluster of ions corresponding to ${ }^{*} \mathrm{e}-\mathrm{H}-\mathrm{H}_{2} \mathrm{O}$ and ${ }^{*} \mathrm{e}+\mathrm{H}-\mathrm{H}_{2} \mathrm{O}$ between $325.22\left(\mathrm{C}_{21} \mathrm{H}_{25} \mathrm{D}_{2} \mathrm{~N}_{2} \mathrm{O},\left[^{2} \mathrm{H}_{2}\right]^{*} \mathrm{e}-\mathrm{H}-\mathrm{H}_{2} \mathrm{O}\right]$ and 328.25 $\left(\mathrm{C}_{21} \mathrm{H}_{26} \mathrm{D}_{3} \mathrm{~N}_{2} \mathrm{O},\left[{ }^{2} \mathrm{H}_{3}\right]^{*} \mathrm{e}+\mathrm{H}-\mathrm{H}_{2} \mathrm{O}\right)$. As in the spectrum of $\mathrm{C}^{4}-7 \alpha, 27$-diol-3-one fragment ions are also observed at $203.15\left({ }^{\#} \mathrm{C}_{2}+2 \mathrm{H}-\mathrm{H}_{2} \mathrm{O}\right)$.

As in the spectra of oxysterol GP hydrazones, [M-79$18]^{+}$and $[\mathrm{M}-107-18]^{+}$ions are observed in the spectra of the 27-oic acids. The presence of these ions at $\mathrm{m} / \mathrm{z} 458.38$ (RA $2 \%$ ) and 430.38 (RA 2\%) in the spectrum of $\left[16,16,17\right.$ (or 20),22,22,23,23- $\left.{ }^{2} \mathrm{H}_{7}\right] \mathrm{CA}^{4}$-3-one (XVII) shows that water can be eliminated from the $\mathrm{C}-27$ acid group. In the spectra of the 7-hydroxy acids the intensity of the [M-79-18] $^{+}$and $[\mathrm{M}-107-18]^{+}$ions at 474.37 (RA 5\%) and 446.38 (RA 5\%) are enhanced, and additional minor intensity peaks at $456.36(\mathrm{RA}<2 \%)$ and 428.37 (RA $2 \%$ ) corresponding to $[\mathrm{M}-79-(2 \times 18)]^{+}$and $[\mathrm{M}-107-(2 \times 18)]^{+}$ are observed. Predictably, the spectra of the 24-methyl esters of the $\left[16,16,17\right.$ (or 20),22,22,23,23- $\left.{ }^{2} \mathrm{H}_{7}\right] \mathrm{CA}^{4}-7-\mathrm{ol}-3-$ one GP hydrazones ( $\mathbf{X X}$ and $\mathbf{X X I})$ show [M-79-18] , [M-79-32] $^{+}$, and [M-79-18-32] ${ }^{+}$at $\mathrm{m} / \mathrm{z} 488.39$ (RA 5\%), $474.37\left(\mathrm{RA}<1 \%\right.$ ), and 456.36 (RA $1 \%$ ); and $[\mathrm{M}-107-18]^{+}$, [M-107-32] $^{+}$, and [M-107-18-32] $]^{+}$at $\mathrm{m} / \mathrm{z} 460.39$ (RA 2\%) 446.38 (RA $<1 \%$ ) and 428.37 (RA $<2 \%$ ), respectively.

The $\mathrm{C}_{24}$ bile acid $3 \beta$-hydroxychol-5-en-24-oic acid, its $\left[2,2,4,4,23-{ }^{2} \mathrm{H}_{5}\right]$ isotopomer and glycine conjugate, and also $3 \beta, 7 \alpha$-dihydroxychol-5-en-24-oic acid, were oxidized with cholesterol oxidase, reacted with GP hydrazine, and analyzed by ES mass spectrometry. Oxidation of these bile acids with cholesterol oxidase results in conversion of the $3 \beta$-hydroxyl group to a ketone, and movement of the $\Delta^{5(6)}$ double-bond to $\Delta^{4(5)}$. In this translocation one of the deuterium atoms on C-4 of the deuterated isotopomers is lost to give a mass increase overall of 4 Da (i.e., $\left[2,2,4,23-{ }^{2} \mathrm{H}_{4}\right]$ ) compared to the unlabeled isotopomer (other isotopomers present include $\left[{ }^{2} \mathrm{H}_{3}\right]$ and $\left[{ }^{2} \mathrm{H}_{5}\right]$, and to a lesser extent $\left[{ }^{2} \mathrm{H}_{1}\right]$ and $\left.\left[{ }^{2} \mathrm{H}_{6}\right]\right)$. The CID spectrum of BA ${ }^{4}$-3-one (XXII) showed the classical fragmentation pattern of a 3 -oxo- $\Delta^{4}$ GP hydrazone. The interpretation of this CID spectrum was then confirmed by recording the analogous spectrum of the $\left[2,2,4,23-{ }^{2} \mathrm{H}_{4}\right]$ isotopomer (XXIII) (see Supplementary Material Figure S-3). As anticipated ${ }^{*} b_{1}-12,{ }^{*} b_{2^{-}}$ $\mathrm{CH}_{2} /{ }^{\#} \mathrm{~b}_{2}-\mathrm{C}_{2} \mathrm{H}_{4}$, and ${ }^{\#} \mathrm{~b}_{2}$ ions were shifted up in mass by $3 \mathrm{Da}$, as were ${ }^{*} b_{1}-12,{ }^{*} b_{2}-\mathrm{CH}_{2} /{ }^{*} b_{2}-\mathrm{C}_{2} \mathrm{H}_{4}$ and ${ }^{*} b_{2}$ ions (Scheme 3). Notably, ${ }^{*} \mathrm{C}_{2}$ was also observed shifted up by $3 \mathrm{Da}$ from $\mathrm{m} / \mathrm{z} 231.15$ to 234.17 . The glycine conjugate of the $\left[2,2,4,23-{ }^{2} \mathrm{H}_{4}\right]$ isotopomer gave a similar series of fragment ions. Due to the inhomogeneity of isotopomers of $\left[{ }^{2} \mathrm{H}_{4}\right] \mathrm{BA}^{4}-3$-one and its glycine conjugate, many fragments were observed as +2 and $+3 \mathrm{Da}$ doublets. Incorporation of a $7 \alpha$-hydroxy group in the bile acid structure, results in a change in the pattern of B-ring fragments. As was the case with other 7-hydroxy-3-oxo- $\Delta^{4}$-GP hydrazones, in the CID spectrum of $\mathrm{BA}^{4}-7 \alpha$-ol-3-one $(\mathbf{X X V})$ the B-ring fragment ion peaks ${ }^{\#} \mathrm{~b}_{2}-\mathrm{CH}_{2}\left(\mathrm{~m} / \mathrm{z}\right.$ 135.09), ${ }^{\prime} \mathrm{b}_{2}(\mathrm{~m} / \mathrm{z} 149.11),{ }^{*} \mathrm{~b}_{2}-\mathrm{CH}_{2}(\mathrm{~m} / \mathrm{z}$ $163.09)$ and ${ }^{*} b_{2}(m / z$ 177.10) are attenuated, while peaks at $123.09\left({ }^{*} \mathrm{~b}_{1}-12\right), 151.09\left({ }^{*} \mathrm{~b}_{3}-\mathrm{C}_{2} \mathrm{H}_{4} /{ }^{*} \mathrm{~b}_{1}-12\right)$ and 179.08 $\left({ }^{*} \mathrm{~b}_{3}-\mathrm{C}_{2} \mathrm{H}_{4}\right)$ are accentuated. Again the presence of the labile $7 \alpha$-hydroxy group had the effect of enhancing the intensity of [M-79-18] ${ }^{+}$and $[\mathrm{M}-107-18]^{+}$ions.

When 22-oxocholesterol was oxidized with cholesterol oxidase and treated with GP hydrazine, two major peaks were observed in the ES mass spectrum at $\mathrm{m} / \mathrm{z}$ 532.39 and 333.23. The peak at 532.39 corresponds to the mono-GP hydrazone $(\mathbf{X})$ and that at 333.23 to the doubly charged bis-GP hydrazone (XI). CID of the mono-GP hydrazone gives the expected series of ring fragments for a 3-oxo- $\Delta^{4}$ 3-GP hydrazone, i.e., " $\mathrm{b}_{1}-12$ (123.09), " ${ }^{\circ} b_{2}-\mathrm{CH}_{2} /{ }^{*} \mathrm{~b}_{3}-\mathrm{C}_{2} \mathrm{H}_{4}$ (135.09), " $\mathrm{b}_{2}$ (149.11), " $\mathrm{b}_{1}-12$ 
(151.09), ${ }^{*} b_{2}-\mathrm{CH}_{2} /{ }^{*} \mathrm{~b}_{3}-\mathrm{C}_{2} \mathrm{H}_{4}(163.09),{ }^{*} \mathrm{~b}_{2}$ (177.10), and ${ }^{*} \mathrm{c}_{2}$ (231.15); but with enhanced abundance of fragment ions at $282.22\left(\mathrm{C}_{20} \mathrm{H}_{28} \mathrm{~N}\right), \quad 297.23 \quad\left(\mathrm{C}_{20} \mathrm{H}_{29} \mathrm{~N}_{2}\right), \quad 312.27$ $\left(\mathrm{C}_{22} \mathrm{H}_{34} \mathrm{~N}\right), 325.23\left(\mathrm{C}_{21} \mathrm{H}_{29} \mathrm{~N}_{2} \mathrm{O}\right), 327.28\left(\mathrm{C}_{22} \mathrm{H}_{35} \mathrm{~N}_{2}\right)$, and $355.27\left(\mathrm{C}_{23} \mathrm{H}_{35} \mathrm{~N}_{2} \mathrm{O}\right)$ corresponding to ${ }^{*} \mathrm{e}-\mathrm{H}-\mathrm{NH},{ }^{\#} \mathrm{e}-\mathrm{H},{ }^{*} \mathrm{f}$ $+\mathrm{H}-\mathrm{NH},{ }^{*} \mathrm{e}-\mathrm{H},{ }^{\#} \mathrm{f}+\mathrm{H}$ and ${ }^{*} \mathrm{f}+\mathrm{H}$ or ${ }^{\#} \mathrm{~g}+\mathrm{H}$, respectively (Figure $2 \mathrm{f}$ ). Both ${ }^{*} \mathrm{f}+\mathrm{H}$ and ${ }^{\#} \mathrm{~g}+\mathrm{H}$ fragments have the elemental composition $\mathrm{C}_{23} \mathrm{H}_{35} \mathrm{~N}_{2} \mathrm{O}$. The absence of an ion at $\mathrm{m} / \mathrm{z} 355.27$ in the CID spectrum of the [M-107] ion, but the presence of an ion at $\mathrm{m} / \mathrm{z} 327.28$ corresponding to the ${ }^{\#_{f}}+\mathrm{H}$ fragment in the spectrum (data not shown), strongly suggests that the ion of $\mathrm{m} / \mathrm{z} 355.27$ in the spectrum of the $[\mathrm{M}]^{+}$ion corresponds to a ${ }^{*} \mathrm{f}+\mathrm{H}$ fragment. In the low mass range of the spectrum, the usual pattern of fragment ions at $\mathrm{m} / \mathrm{z}$ 80.05, 94.07, $108.08,109.08,120.05 / 120.08$ and 137.07 is distorted by the presence of ions at $\mathrm{m} / \mathrm{z} 81.07$ and 99.08 . These ions correspond to hydrocarbon fragments with chemical formulas $\mathrm{C}_{6} \mathrm{H}_{9}$, and $\mathrm{C}_{6} \mathrm{H}_{11} \mathrm{O}$ formed by cleavage of the $\mathrm{C}-20-\mathrm{C}-22$ bond $\alpha$ to the carbonyl group at $\mathrm{C}-22$. The $\mathrm{C}_{6} \mathrm{H}_{9}\left(\mathrm{~F}-\mathrm{H}_{2} \mathrm{O}\right)$ fragment is probably derived by water loss from $\mathrm{C}_{6} \mathrm{H}_{11} \mathrm{O}(\mathrm{F})$ (Scheme 5). The structural significance of these low-mass fragment ions observed in the CID spectrum of $C^{4}$-3,22-dione 3-GP hydrazone encouraged us to reinspect the low mass regions of our spectra (see below).

In the CID spectrum of the $[\mathrm{M}]^{2+}$ ion of the bis-GP hydrazone $(\mathbf{X I})$ the low mass range is also different to that normally observed for a 3-oxo- $\Delta^{4} \mathrm{GP}$ hydrazone, in that additional peaks are observed at $m / z 91.05\left(\mathrm{C}_{7} \mathrm{H}_{7}\right)$ and $112.11\left(\mathrm{C}_{7} \mathrm{H}_{14} \mathrm{~N}\right)$. The characteristic " $\mathrm{b}_{1}-12(123.09)$, ${ }^{*} \mathrm{~b}_{2}-\mathrm{CH}_{2} /{ }^{{ }^{*}} \mathrm{~b}_{3}-\mathrm{C}_{2} \mathrm{H}_{4}$ (135.09), ${ }^{*} \mathrm{~b}_{1}-12$ (151.09), and ${ }^{*} \mathrm{~b}_{2}$ $\mathrm{CH}_{2} /{ }^{*} \mathrm{~b}_{2}-\mathrm{C}_{2} \mathrm{H}_{4}$ (163.09) ions are observed, but are of minor abundance. The presence of the substituent on C-22 facilitates cleavage of the C-20-C-22 bond with the formation of a ${ }^{*} \mathrm{f}-\mathrm{H}$ (353.26) fragment. The spectrum is dominated by fragment ions formed by losses from the GP hydrazone group giving doubly charged ions at $\mathrm{m} / \mathrm{z}$ $293.71\left([\mathrm{M}-79]^{2+}, \mathrm{C}_{36} \mathrm{H}_{53} \mathrm{~N}_{5} \mathrm{O}_{2}\right), 279.71\left([\mathrm{M}-107]^{2+}\right.$, $\left.\mathrm{C}_{35} \mathrm{H}_{53} \mathrm{~N}_{5} \mathrm{O}\right), 254.19\left([\mathrm{M}-(79 \times 2)]^{2+}, \mathrm{C}_{31} \mathrm{H}_{48} \mathrm{~N}_{4} \mathrm{O}_{2}\right)$ and 240.19 ([M-79-107] $]^{2+}, \mathrm{C}_{30} \mathrm{H}_{40} \mathrm{~N}_{4} \mathrm{O}$ ). Complementary singly charged ions are observed at $586.41\left([\mathrm{M}-80]^{+}\right.$, $\mathrm{C}_{36} \mathrm{H}_{52} \mathrm{~N}_{5} \mathrm{O}_{2}$ ) and $507.37\left([\mathrm{M}-79-80]^{+}, \mathrm{C}_{31} \mathrm{H}_{47} \mathrm{~N}_{4} \mathrm{O}_{2}\right.$ ), and additional singly charged fragments are observed at $544.40\left([\mathrm{M}-122]^{+}, \mathrm{C}_{34} \mathrm{H}_{50} \mathrm{~N}_{5} \mathrm{O}\right), 543.41$ ([M-107-16 $]^{+}$, $\mathrm{C}_{35} \mathrm{H}_{51} \mathrm{~N}_{4} \mathrm{O}$ ), $516.40\left([\mathrm{M}-150]^{+}, \mathrm{C}_{34} \mathrm{H}_{50} \mathrm{~N}_{3} \mathrm{O}\right.$ ), 465.36 ([M107-94] $\left.{ }^{+}, \mathrm{C}_{29} \mathrm{H}_{45} \mathrm{~N}_{4} \mathrm{O}\right), 464.36\left(\mathrm{C}_{30} \mathrm{H}_{46} \mathrm{~N}_{3} \mathrm{O}\right)$, and 437.35 ([M-79-150] $]^{+}, \mathrm{C}_{29} \mathrm{H}_{45} \mathrm{~N}_{2} \mathrm{O}$ ).

Group (iv) fragment ions: Hydrocarbon ions. To aid the interpretation of the hydrocarbon fragment ion pattern formed by 3-oxo- $\Delta^{4}$ sterol GP hydrazones it is advantageous to consider the CID spectra of the simplest $C_{27}$ steroid, i.e., $\mathrm{C}^{4}$-3-one GP hydrazone (I) (Figure 3c), and of a simple $C_{19}$ steroid, i.e., $A^{4}-17 \beta$-ol-3-one GP hydrazone (XXVI) (spectrum not shown). Peaks at $m / z 81.07\left(\mathrm{C}_{6} \mathrm{H}_{9}\right)$, 93.07 $\left(\mathrm{C}_{7} \mathrm{H}_{9}\right), 95.09\left(\mathrm{C}_{7} \mathrm{H}_{11}\right), 105.07\left(\mathrm{C}_{8} \mathrm{H}_{9}\right), 107.09\left(\mathrm{C}_{8} \mathrm{H}_{11}\right)$, $109.10\left(\mathrm{C}_{8} \mathrm{H}_{13}\right)$, and $119.09\left(\mathrm{C}_{9} \mathrm{H}_{11}\right)$ are observed in both spectra indicating that they are derived from the steroid ring system. There is enhanced intensity at $\mathrm{m} / \mathrm{z} 95.09$, 107.09 and 109.10 and an additional peak at $111.12\left(\mathrm{C}_{8} \mathrm{H}_{15}\right)$ in the spectrum of $\mathrm{C}^{4}$-3-one GP hydrazone demonstrating that these peaks are additionally derived from the sidechain. At higher mass, fragment ions are observed at $201.16\left(\mathrm{C}_{15} \mathrm{H}_{21}\right)$, and $253.20\left(\mathrm{C}_{19} \mathrm{H}_{25}\right)$ in the spectrum of $\mathrm{A}^{4}-17 \beta$-ol-3-one corresponding to the doubly unsaturated $A B C$ ring system, and the triply unsaturated steroid ABCD-ring system plus C-18 and C-19, respectively, (Scheme 5). These ions are present in the spectrum of $\mathrm{C}^{4}$-3-one GP hydrazone, but are of low abundance, instead a fragment ion is observed at $367.34\left(\mathrm{C}_{27} \mathrm{H}_{43}\right)$ corresponding to the cholestane skeleton with two double bonds. Compared with this template, the CID spectra of 3-oxo- $\Delta^{4}$ sterol GP hydrazones show many similarities.

The isomers of monohydroxylated $C^{4}$-3-one GP hydrazone (V-IX) show the same pattern of low mass fragments as $\mathrm{C}^{4}$-3-one GP hydrazone (Figure 2a-e). At higher mass peaks at $m / z 199.15\left(\mathrm{C}_{15} \mathrm{H}_{19}\right), 253.20\left(\mathrm{C}_{19} \mathrm{H}_{25}\right)$ and 365.32 $\left(\mathrm{C}_{27} \mathrm{H}_{41}\right)$ are observed consistently; while a peak at $\mathrm{m} / \mathrm{z}$ $383.33\left(\mathrm{C}_{27} \mathrm{H}_{43} \mathrm{O}\right)$ corresponding to doubly unsaturated cholestanol is observed in the spectra of the $7 \beta$-hydroxyand 27-hydroxy-isomers (Scheme 5). The 7-hydroxy isomer additionally gives fragment ions at $\mathrm{m} / \mathrm{z} 247.24$ $\left(\mathrm{C}_{18} \mathrm{H}_{31}, \mathrm{~B}_{3}-\mathrm{H}\right)$, and $287.27\left(\mathrm{C}_{21} \mathrm{H}_{35}, \mathrm{~B}_{1}+12+\mathrm{H}-\mathrm{H}_{2} \mathrm{O}\right)$ (Scheme 5). These ions are complementary to $b_{3}$-type and $b_{1}-12$ type fragments respectively, and their formation is encouraged by the presence of the $7 \beta$-hydroxyl group. The dihydroxylated versions of $\mathrm{C}^{4}$-3-one carrying hydroxyl groups in the side-chain and at $\mathrm{C}-7$ give essentially the same pattern of low mass fragment ions as their monohydroxy analogs, this is also true in the higher mass range, however, the peak at $\mathrm{m} / \mathrm{z} 365.32$ is now shifted to $363.31\left(\mathrm{C}_{27} \mathrm{H}_{39}\right)$, that at 383.33 to $381.32\left(\mathrm{C}_{27} \mathrm{H}_{41} \mathrm{O}\right)$, and that at 247.24 to $245.23\left(\mathrm{C}_{18} \mathrm{H}_{29}, \mathrm{~B}_{3}-\mathrm{H}-\mathrm{H}_{2} \mathrm{O}\right)$, while the peak at $\mathrm{m} / \mathrm{z} 287.27$ is no longer observed (Figure $3 \mathrm{a}$, and Supplementary Material Figure S-1). Incorporation of two hydroxyl groups on the side-chain as in $C^{4}$-20R,22R-diol3-one (XII), has a major effect on the pattern of low mass hydrocarbon fragment ions (Figure $3 \mathrm{~b}$ ). In the low mass range, the dominant fragment ion is now at 109.10 $\left(\mathrm{C}_{8} \mathrm{H}_{13}\right)$; this is more intense than the fragment ions at $\mathrm{m} / \mathrm{z}$ $94.07\left(\sigma_{2}+\mathrm{H}, \mathrm{C}_{6} \mathrm{H}_{8} \mathrm{~N}\right), 108.08\left(\mathrm{C}_{7} \mathrm{H}_{10} \mathrm{~N}\right)$, and $120.05\left(\sigma_{3}-\mathrm{H}\right.$, $\left.\mathrm{C}_{7} \mathrm{H}_{6} \mathrm{NO}\right)$, which normally dominate this region of the spectrum. The ion at $m / z 109.10\left(\mathrm{C}_{8} \mathrm{H}_{13}\right)$ corresponds to a doubly unsaturated side-chain fragment formed by cleavage of the C-17-C-20 bond $\alpha$ to the $\mathrm{C}-20$ hydroxyl group, i.e., $\mathrm{E}-\left(2 \mathrm{xH}_{2} \mathrm{O}\right)$. In the higher mass range essentially only the hydrocarbon fragment ion at $253.20\left(\mathrm{C}_{19} \mathrm{H}_{25}\right)$ is observed.

As discussed above, the low mass pattern of fragment ions is distorted in the CID spectra of $\mathrm{C}^{4}$-3,22-dione 3-GP hydrazone $(\mathbf{X})$ (Figure 2f). Ions at $m / z 81.07\left(\mathrm{C}_{6} \mathrm{H}_{9}\right)$ and $99.08\left(\mathrm{C}_{6} \mathrm{H}_{11} \mathrm{O}\right)$ corresponding to fragments formed by cleavage of the C-20-C-22 bond $\alpha$ to the carbonyl group now dominate this region of the spectrum. The $\mathrm{C}_{6} \mathrm{H}_{9}$ fragment is probably derived by water loss from $\mathrm{C}_{6} \mathrm{H}_{11} \mathrm{O}$. 
<smiles>CC12C=CCC1C1CCC(C)(C(F)(F)F)C3(CC=CC=CC3)C1CC2</smiles><smiles>CC12CC=CC=C1CCC1CCCCC12</smiles>

$\mathrm{C}_{15} \mathrm{H}_{21}{ }^{+}$ Exact Mass: 201.16<smiles></smiles><smiles></smiles>

$[\mathrm{M}]^{+}$

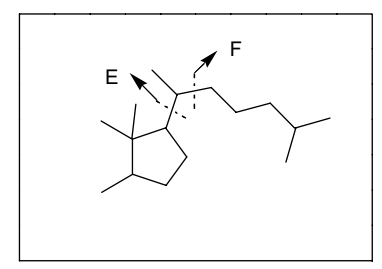<smiles>CC12CC=CC=C1C=CC1C(CC2)C2CCCC12C</smiles><smiles>[131IH]</smiles>
Exact Mass: 253.20

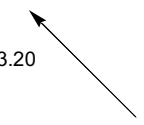<smiles>CC12CC=CC=C1C=CC1CCCCC12</smiles>

$\mathrm{C}_{15} \mathrm{H}_{19}{ }^{+}$

Exact Mass: 199.15

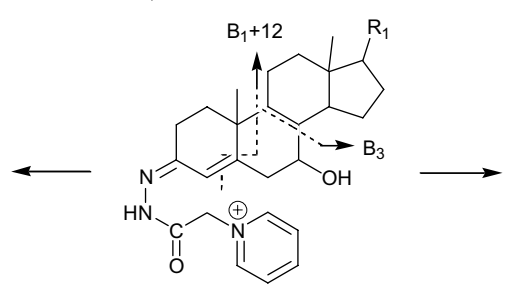

$[\mathrm{M}]^{+}$

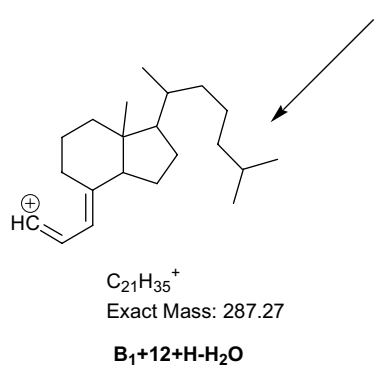

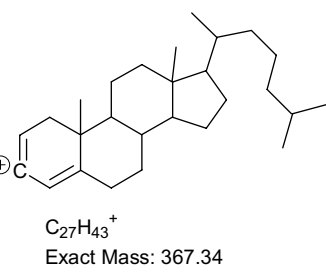

Exact Mass: 367.34<smiles>CC(C)CCCC(C)C1CCC2C3C(O)CC4=CC=CCC4(C)C3CCC12C</smiles>

Exact Mass: 383.33

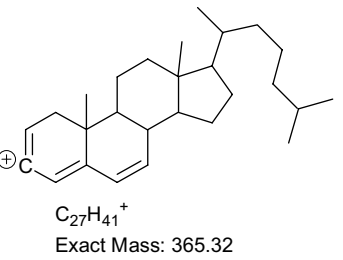

Exact Mass: 365.32

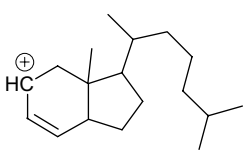

$\mathrm{C}_{18} \mathrm{H}_{31}{ }^{+}$

Exact Mass: 247.24

$\mathrm{B}_{3}-\mathrm{H}$

Scheme 5. Hydrocarbon fragment ions formed from 3-oxo- $\Delta^{4}$ steroid 3-GP hydrazones. The presence of a hydroxyl group on the $\mathrm{C}-17$ side-chain will result in additional unsaturation and a reduction in fragment ion mass by $2.02 \mathrm{Da}$.

\section{Cholesterol, Cholestadienes, and Side-Chain}

\section{Modified Cholesterols: Compounds I-IV}

\section{(see Table 1)}

During the analysis of oxysterols from biological sources possibly the oxysterol fractions may be contaminated with cholesterol, its precursors, and possibly by plant sterols present from the diet. We have thus oxidized and derivatized cholesterol, its precursor des- mosterol $\left(\mathrm{C}^{5,24}-3 \beta-\mathrm{ol}\right)$, and the plant sterols stigmasterol (24 $\beta$-ethyl-cholesta-5,22-dien-3 $\beta$-ol, $C^{5,22}-24 \beta$-ethyl-3 $\beta$ $\mathrm{ol})$, and sitosterol ( $24 \beta$-ethyl-cholest-5-en-3 $\beta$-ol, $C^{5}-24 \beta$ ethyl-3 $\beta$-ol) and analyzed their GP hydrazones.

Desmosterol is a precursor in the de novo synthesis of brain cholesterol [54]. When oxidized with cholesterol oxidase and derivatized with GP hydrazine, CID of the resulting $\mathrm{C}^{4,24}$-3-one GP hydrazone (II) gives a 


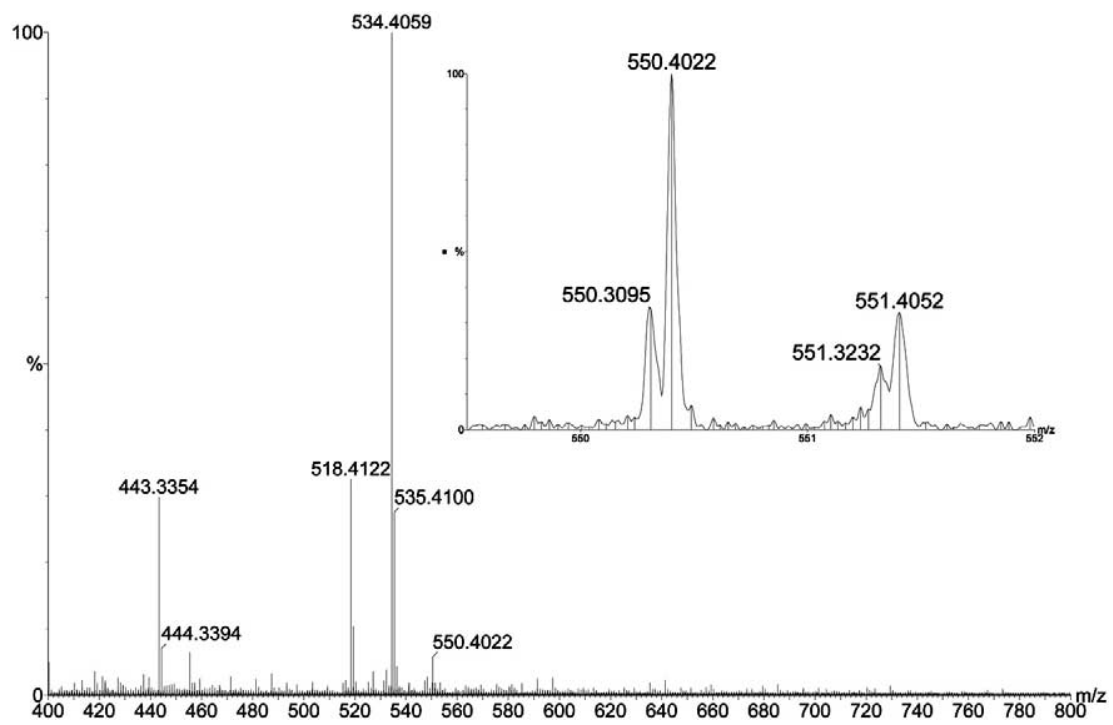

Figure 4. Mass spectrum of the oxidized and derivatized oxysterol fraction of rat brain. The amount of sample loaded into the ES-capillary corresponded to $\sim 40 \mu \mathrm{g}$ of brain. Spectrum recorded on the Q-TOF Global instrument in "W-mode". The y axis represents relative abundance.

spectrum essentially similar to those of other 3-oxo- $\Delta^{4}$ steroids (see Supplementary Material Figure S-4). However, peaks at $353.26\left(\mathrm{C}_{23} \mathrm{H}_{33} \mathrm{~N}_{2} \mathrm{O}\right)$ and 355.27 $\left(\mathrm{C}_{23} \mathrm{H}_{35} \mathrm{~N}_{2} \mathrm{O}\right)$ corresponding to ${ }^{*} \mathrm{f}-\mathrm{H}$ and ${ }^{*} \mathrm{f}+\mathrm{H}$; and $325.26\left(\mathrm{C}_{22} \mathrm{H}_{33} \mathrm{~N}_{2}\right)$ and $327.28\left(\mathrm{C}_{22} \mathrm{H}_{35} \mathrm{~N}_{2}\right)$ correspond to ${ }_{\mathrm{f}} \mathrm{H}-\mathrm{H}$ and ${ }_{\mathrm{f}}+\mathrm{H}$, are of elevated intensity. These ions are formed by cleavage of the bond between C-20 and C-22 with hydrogen transfer from $(\mathrm{f}-\mathrm{H})$, and to $(\mathrm{f}+\mathrm{H})$, the ionic fragment.

The level of the plant sterol sitosterol in serum is often used as a marker for cholesterol absorption. Sterol esters, including those of sitosterol and stigmasterol, are present in phytosterol ester enriched low-fat food products, and their consumption has been shown to reduce serum total and LDL cholesterol levels $[55,56]$. Conversely, phytosterol levels in plasma become elevated upon consumption of these foods [55]. The CID spectra of $C^{4}$-24 $\beta$-ethyl-3-one (III) and $C^{4,22}-24 \beta$-ethyl-3-one (IV) GP hydrazones showed the common features of 3-oxo- $\Delta^{4}$ GP hydrazones (Figure $3 \mathrm{~d}$ and Supplementary Material Figure S-4). The spectrum of $C^{4}-24 \beta$-ethyl-3one (III) was very similar to that of $C^{4}$-3-one (I), however, the peak at $367.34\left(\mathrm{C}_{27} \mathrm{H}_{43}\right)$ in the spectrum of $\mathrm{C}^{4}$-3-one, and corresponding to the doubly unsaturated cholestane skeleton (Scheme 5), was shifted to 395.37 $\left(\mathrm{C}_{29} \mathrm{H}_{47}\right)$ in the spectrum of the $24 \beta$ analog. The presence of the C-22 - C-23 double-bond in $C^{4,22}-24 \beta$-ethyl3 -one (IV) is reflected in the low-mass region of the MS/MS spectrum where the intensity of the ion at $\mathrm{m} / \mathrm{z}$ $83.09\left(\mathrm{C}_{6} \mathrm{H}_{11}\right)$ is greatly enhanced (Figure $\left.3 \mathrm{~d}\right)$. This ion is formed by cleavage of the C-23-C-24 bond $\alpha$ to the $\mathrm{C}-22-\mathrm{C}-23$ double-bond. The C-22-C-23 double-bond also has an effect on other side-chain fragmentations. As in the spectrum of $C^{4}$-20R,22R-diol-3-one GP hydrazone (XII) (Figure $3 b$ ), there is enhanced abundance of fragment ions at $\mathrm{m} / \mathrm{z} 284.24\left(\mathrm{C}_{20} \mathrm{H}_{30} \mathrm{~N},{ }^{*} \mathrm{e}+\mathrm{H}-\mathrm{NH}\right)$,
$299.25\left(\mathrm{C}_{20} \mathrm{H}_{31} \mathrm{~N}_{2},{ }^{*} \mathrm{e}+\mathrm{H}\right)$, and $327.24\left(\mathrm{C}_{21} \mathrm{H}_{31} \mathrm{~N}_{2} \mathrm{O},{ }^{*} \mathrm{e}+\right.$ $\mathrm{H})$, each formed as a result of cleavage of the C-17-C-20 bond, and in the case of $C^{4,22}$-24 $\beta$-ethyl-3-one (IV), $\beta$ to the double-bond. It is interesting to note that a similar triad of fragment ions is observed in the spectrum of $\mathrm{C}^{4}$-3,22-dione 3-GP hydrazone $(\mathbf{X})$ but shift to lower mass by 2 Da (Figure 2f). The CID spectrum of $C^{4,22}$ $24 \beta$-ethyl-3-one is further characterized by peaks at $353.30\left(\mathrm{C}_{24} \mathrm{H}_{37} \mathrm{~N}_{2}\right.$, $\left.{ }^{*} \mathrm{~h}+\mathrm{H}\right)$, and $381.29\left(\mathrm{C}_{25} \mathrm{H}_{37} \mathrm{~N}_{2} \mathrm{O}\right.$, ${ }^{*} \mathrm{~h}+$ $\mathrm{H})$ both formed as a result of cleavage of the C-23-C-24 bond.

\section{Oxysterols in Brain}

To evaluate the analytical method described above the oxysterol content of rat brain was investigated. Oxysterols in rat brain were extracted [36, 37], oxidized with cholesterol oxidase, and derivatized to GP hydrazones. The method has yet to be fully optimized and further details of the extraction procedure will be published when appropriate. Shown in Figure 4 is the ES mass spectrum of the oxidized and derivatized oxysterol fraction of rat brain. The amount of sample loaded into the ES-capillary corresponded to $\sim 40 \mu \mathrm{g}$ of brain. A major peak is observed at $\mathrm{m} / \mathrm{z} 534.41$, which corresponds to the $\mathrm{m} / \mathrm{z}$ of the $[\mathrm{M}]^{+}$ion of a monohydroxy3-oxo- $\Delta^{4} \mathrm{C}_{27}$ steroid GP hydrazone. MS/MS of the ion at $m / z 534.41$ gave the spectrum shown in Figure $2 b$. The low-mass pattern of fragments at $\mathrm{m} / \mathrm{z}$ 80.05, 94.07, $108.08,109.08,120.05$, and 137.07, and the high-mass pattern at $455.36\left([\mathrm{M}-79]^{+}\right)$and $427.37\left([\mathrm{M}-107]^{+}\right)$, confirmed that the precursor ion corresponded to a GP hydrazone. The fragment ion pattern $123.09\left({ }^{*} b_{1}-12\right)$, $135.09\left({ }^{*} \mathrm{~b}_{2}-\mathrm{CH}_{2} /{ }^{*} \mathrm{~b}_{3}-\mathrm{C}_{2} \mathrm{H}_{4}\right), 149.11\left({ }^{*} \mathrm{~b}_{2}\right), 151.09\left({ }^{*} \mathrm{~b}_{1}-12\right)$, $163.09\left({ }^{*} \mathrm{~b}_{2}-\mathrm{CH}_{2} /{ }^{*} \mathrm{~b}_{2}-\mathrm{C}_{2} \mathrm{H}_{4}\right)$, and $177.10\left(\mathrm{~b}_{2}\right)$ are indicative of a 3-oxo- $\Delta^{4}$ GP hydrazone unsubstituted at posi- 
tion C-7 (cf. Figure 2a). Fragment ions are additionally observed at $231.15\left({ }^{*} \mathrm{C}_{2}\right), 285.20\left({ }^{*} \mathrm{~d}_{1}\right), 325.23\left({ }^{*} \mathrm{e}-\mathrm{H}\right)$, $325.26\left({ }^{*} \mathrm{f}-\mathrm{H}\right), 327.24\left({ }^{*} \mathrm{e}+\mathrm{H}\right)$, and especially at 353.26 $\left({ }^{*} \mathrm{f}-\mathrm{H}\right)$, which are consistent with a 24-hydroxycholest4-en-3-one GP hydrazone (VI) structure. 24-Hydroxycholest-4-en-3-one is the product of cholesterol oxidase mediated oxidation of 24-hydroxycholesterol. The identification of 24-hydroxycholesterol in brain is in agreement with the work of Smith and colleagues who showed in 1973 that 24-hydroxycholesterol is the major oxysterol in brain [57], and of Björkhem and colleagues who have shown that in rat about $70 \%$ of the 245 hydroxycholesterol in plasma is of cerebral origin [58]. Exact mass measurements made in the ES mass spectrum shown in Figure 4 suggest the presence of a second 3-oxo- $\Delta^{4}$-steroid GP hydrazone at $m / z$ 550.40. A mass of $550.40 \mathrm{Da}$ corresponds to a dihydroxy-3-oxo- $\Delta^{4}$ $\mathrm{C}_{27}$ steroid GP hydrazone, and CID of the ion at $\mathrm{m} / \mathrm{z}$ 550.40 gives a spectrum indicative of a dihydroxy-3oxo- $\Delta^{4} C_{27}$ steroid GP hydrazone, with probably the two hydroxyl groups on the C-17 side-chain (see Supplementary Material Figure S-1f), but not a 20,22-diol. Many peaks in the CID spectrum of $m / z 550.40$ are not easily explained by a single dihydroxy-3-oxo- $\Delta^{4} C_{27}$ steroid GP hydrazone structure, and it seems likely that more than one compound (isomer) is being subjected to MS/MS. It should be noted, that to obtain sufficient precursor-ion current the resolution of the quadrupole was reduced so as to allow transmission of an $\mathrm{m} / \mathrm{z}$ window of about 2 units. Significantly, the fragment ions at $m / z 120.05\left(\sigma_{3}-\mathrm{H}\right)$, and $137.07\left(\sigma_{4}+\mathrm{H}\right)$ are more abundant than is normally the case with 3 -oxo- $\Delta^{4}$ steroids, and additional fragment ions are observed at 167.12 and 181.13 of unknown origin.

Zhang et al. have demonstrated the conversion of 24-hydroxycholesterol to 24,25-dihydroxycholesterol in cultures of fetal rat astrocytes [59]. In the same study, they showed that 24-hydroxycholesterol is not 7-hydroxylated in these cultures, and it has subsequently been confirmed that CYP7B1 does not 7-hydroxylate 24-hydroxycholesterol. The possibility exists that the 24,25 diol is cleaved by oxidation into a C-24 acid. In brain this would lead to the cholenoic acid that can be 7-hydroxylated [60]. More recently, Mast et al. [61] have shown that CYP46A1, the enzyme responsible for 24Shydroxylation of cholesterol in brain, can further metabolize 24S-hydroxycholesterol to 24,25- and 24,27dihydroxycholesterol in cell cultures transfected with human CYP46A1 cDNA and in an vitro reconstituted system with recombinant enzyme. In vivo studies on the metabolism of 24-hydroxycholesterol in humans have shown that 27-hydroxylation, formation of bile acids and double conjugation are the main pathways of metabolism in man [25].

The apparent inhomogeneity of the precursor ion at $\mathrm{m} / \mathrm{z} 550$ emphasizes the importance of the incorporation of a LC step before mass analysis so as to resolve isomeric compounds in the time domain. Procedures to analyze oxysterol GP hydrazones by capillary-LC-
MS/MS using the Q-TOF instruments and the triple quadrupole are currently being studied in our laboratories, and we show only preliminary data here.

Using the $C_{18}$ capillary column with gradient elution we are able to separate the reference monohydroxy-3oxo- $\Delta^{4} C_{27}$ steroid GP hydrazones. When the brain sample was injected onto the column following oxidation and derivatization, only one chromatographic peak was observed to corresponding to a monohydroxy-3oxo- $\Delta^{4} \mathrm{C}_{27}$ steroid GP hydrazone $\left(\mathrm{M}^{+}, \mathrm{m} / \mathrm{z}\right.$ 534.41) (Figure 5a). The retention time for this compound was identical to that of reference $\mathrm{C}^{4}$-24S-ol-3-one GP hydrazone (VI, $21.04 \mathrm{~min}$ ) and it gave an MS/MS spectrum consistent with this structure (cf Figure 5a inset, Figure 2a and b). Dihydroxy-3-oxo- $\Delta^{4} C_{27}$ steroid GP hydrazones give an $\mathrm{M}^{+}$ion at $m / z 550.40$. A reconstructed ion chromatogram (RIC) for this ion in the brain sample gave at least four chromatographic peaks (Figure 5b), one of which gave an MS/MS spectrum of a dihydroxy3-oxo- $\Delta^{4} C_{27}$ steroid GP hydrazones where both hydroxyl groups are probably on the C-17 side-chain (Figure 5b).

\section{Discussion}

\section{Fragmentation of 3-Oxo- $\Delta^{4}$ Steroids and Their Cationic Derivatives}

The fragmentation reactions of 3-oxo- $\Delta^{4}$ steroids, their 3 -oxime, and Girard hydrazone derivatives have previously been investigated [38-40, 49, 50,52]. There is general agreement as to the structure of the $b_{1}-12$ and $b_{2}$ type ions, but some debate as to the structure of the $\mathrm{b}_{2}-\mathrm{CH}_{2}$ type ions [53]. The use of deuterium labeled steroids in this current study provide further evidence for the $b_{1}-12$ type ions to consist of the steroid A-ring plus $\mathrm{C}-19$ but minus $\mathrm{C}-5$; and the $\mathrm{b}_{2}$ type ions to consist of the A ring, C-6 and C-19 (Scheme 3). The structure of the $\mathrm{b}_{2}-\mathrm{CH}_{2}$ type ions is less clear-cut. After performing detailed stable-isotope labeling studies Liu et al. [49] proposed that these ions contain the A-ring and C-6, but that $\mathrm{C}-19$ has been lost and replaced by $\mathrm{H}$-atom from $\mathrm{C}-7$ or the CD-rings. In addition, the $6 \beta-\mathrm{H}$ has been replaced by an $\mathrm{H}$-atom from $\mathrm{C}-7$ or the $\mathrm{CD}$-rings. A better description for these types of ions is thus $b_{2}$ $\mathrm{CH}_{3}-\mathrm{H}+2 \mathrm{H}$ (Scheme 3 ). In contrast to this explanation, Williams et al. [52] in their study of testosterone and hydroxylated versions thereof proposed that Liu's $b_{2^{-}}$ $\mathrm{CH}_{2}$ ions consist of the A-ring, plus C- 6 and C-7 but minus $\mathrm{C}-10$ and $\mathrm{C}-19$ and a $\mathrm{H}$-atom from C-6. (Scheme 3 ), and are thus better described as $\mathrm{b}_{3}-\mathrm{C}_{2} \mathrm{H}_{4}$ ions. In the current study, when a 7-hydroxyl group was incorporated into the 3-oxo- $\Delta^{4}$ structure, GP hydrazone fragment ions were observed at $\mathrm{m} / \mathrm{z} 135.09$ and 163.09, corresponding to ions with the elemental composition $\mathrm{C}_{8} \mathrm{H}_{11} \mathrm{~N}_{2}\left({ }^{*} \mathrm{~b}_{2}-\mathrm{CH}_{2}\right)$ and $\mathrm{C}_{9} \mathrm{H}_{11} \mathrm{~N}_{2} \mathrm{O}\left({ }^{*} \mathrm{~b}_{2}-\mathrm{CH}_{2}\right)$, respectively, but at reduced abundance (Figure 2). According to Liu's structure, such ions would be better described as $\mathrm{b}_{2}-\mathrm{CH}_{3}-\mathrm{H}+2 \mathrm{H}$ type ions. Williams' $\mathrm{b}_{3}-\mathrm{C}_{2} \mathrm{H}_{4}$ type 


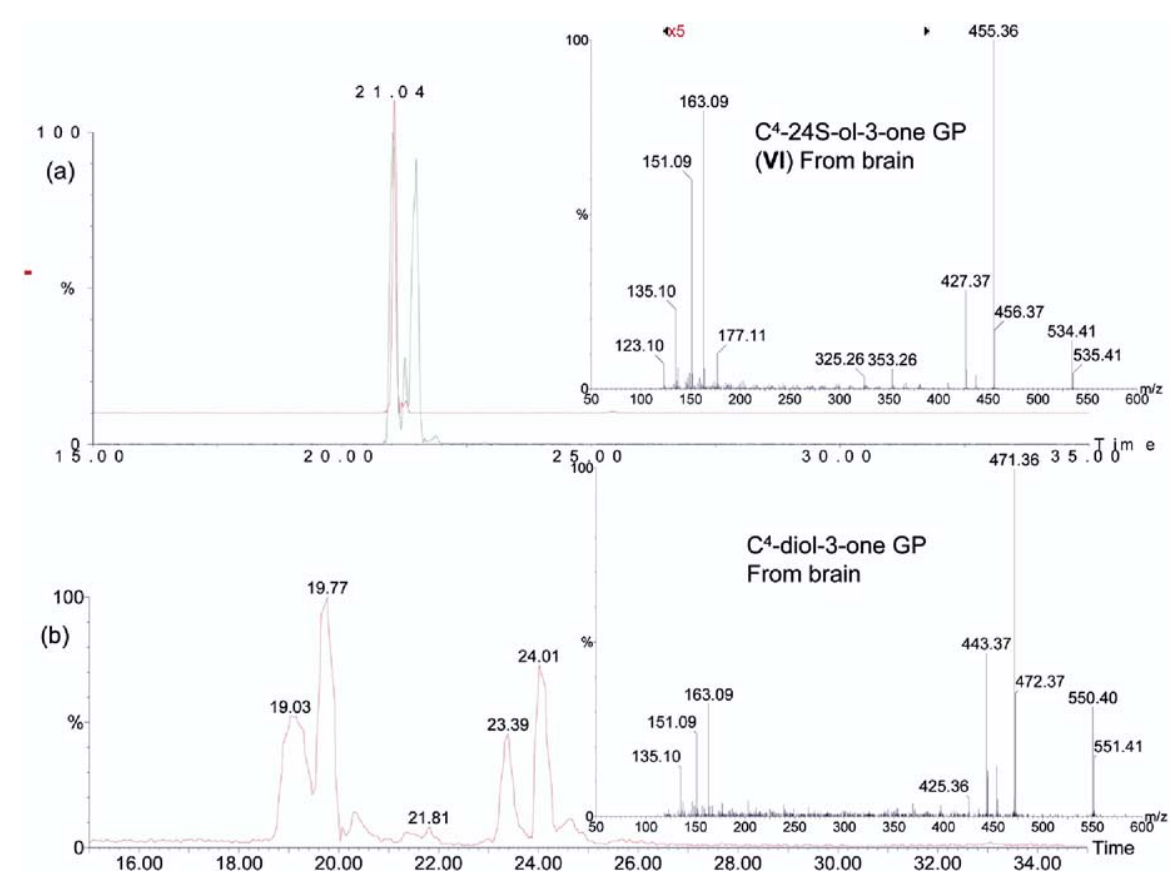

Figure 5. (a) RICs for a reference mixture of $C^{4}$-24S-ol-3-one GP and $C^{4}$-24R-ol-3-one GP (green lower trace); and $\mathrm{C}^{4}-24 \mathrm{~S}$-ol-3-one GP (red upper trace) from the brain sample after oxidation and derivatization. The inset shows the MS/MS spectrum of $\mathrm{m} / \mathrm{z} 534.41$ (retention time $21.04 \mathrm{~min}$ ) from brain. (b) RIC for $m / z 550.40$ from the brain sample following oxidation and derivatization. The inset shows the MS/MS spectrum of $\mathrm{m} / \mathrm{z} 550.40$ eluting at $19.03 \mathrm{~min}$. Spectra were recorded on the Q-TOF Global in the "V-mode".

ions would not have $\mathrm{m} / \mathrm{z}$ values of 135.09 and 163.09 , but rather $151.09\left(\mathrm{C}_{8} \mathrm{H}_{11} \mathrm{~N}_{2} \mathrm{O}\right)$ and $179.08\left(\mathrm{C}_{9} \mathrm{H}_{11} \mathrm{~N}_{2} \mathrm{O}_{2}\right)$, respectively. Thus, the observation of fragment ions at $\mathrm{m} / \mathrm{z} 135.09$ and 163.09 in the spectra of 7-hydroxy-3oxo- $\Delta^{4}$ steroids indicates that a reaction channel exists for the formation of ions with Liu's $\mathrm{b}_{2}-\mathrm{CH}_{3}-\mathrm{H}+2 \mathrm{H}$ structure (Figure 2e, Scheme 3). The presence of a 7-hydroxyl group on the steroid skeleton does results also in the formation of fragment ions at $\mathrm{m} / \mathrm{z} 179.08$, these ions could be formed by cleavage between C- 6 and $\mathrm{C}-7$ with the accompanying loss of $\mathrm{C}-19$ and $6 \beta-\mathrm{H}$, but with the gain of a $\mathrm{H}$-atom from the $\mathrm{CD}$ ring and an $\mathrm{OH}$ group from $\mathrm{C}-7$, i.e., ${ }^{*} \mathrm{~b}_{2}-\mathrm{CH}_{3}-\mathrm{H}+\mathrm{H}+\mathrm{OH}$ (Figure $2 \mathrm{e}$, Scheme 3). Alternatively, the ion at $m / z 179.08$ could simply be of the structure ${ }^{*} b_{3}-C_{2} H_{4}$ as suggested by Williams et al. The equivalent ${ }^{*} \mathrm{~b}_{2}-\mathrm{CH}_{3}-\mathrm{H}+\mathrm{H}+\mathrm{OH}$ and ${ }^{*} \mathrm{~b}_{3}-\mathrm{C}_{2} \mathrm{H}_{4}$ ions appear at $\mathrm{m} / \mathrm{z} 151.09$, as do ${ }^{*} \mathrm{~b}_{1}-12$ ions. The dominant b-type ions in the CID spectra of 7-hydroxy-3-oxo- $\Delta^{4}$ steroid GP hydrazones appear at $m / z 123.09\left(\mathrm{C}_{7} \mathrm{H}_{11} \mathrm{~N}_{2},{ }^{*} \mathrm{~b}_{1}-12\right)$ and $151.09\left(\mathrm{C}_{8} \mathrm{H}_{11} \mathrm{~N}_{2} \mathrm{O}\right.$, ${ }^{*} \mathrm{~b}_{1}-12$ or ${ }^{*} \mathrm{~b}_{2}-\mathrm{CH}_{3}-\mathrm{H}+\mathrm{H}+\mathrm{OH}$ and ${ }^{\#} \mathrm{~b}_{3}-\mathrm{C}_{2} \mathrm{H}_{4}$ ) (Figures 2e, 3a, and Supplementary Material Figure S-1). This prominence of $b_{1}-12$ type ions can be explained by the lability of the C-7 hydroxyl group and its propensity to eliminate as water and generate a double-bond between C-6 and C-7, thereby attenuating alternative b-type fragmentation channels. The overriding abundance of the ion at $\mathrm{m} / \mathrm{z} 151.09$ is probably a consequence of the fact that different fragment ions, i.e., ${ }^{\#} \mathrm{~b}_{2}-\mathrm{CH}_{3}-\mathrm{H}+\mathrm{H}+$ $\mathrm{OH},{ }^{*} \mathrm{~b}_{3}-\mathrm{C}_{2} \mathrm{H}_{4}$, and ${ }^{*} \mathrm{~b}_{1}-12$, each has an identical elemen- tal composition and a mass of 151.09 and each contributes to the ion current giving this peak.

In summary, the results of the current study indicate that Liu's $\mathrm{b}_{2}-\mathrm{CH}_{3}-\mathrm{H}+2 \mathrm{H}$ type ions can be formed, but do not allow the differentiation of $b_{3}-C_{2} \mathrm{H}_{4}$ from $b_{2}$ $\mathrm{CH}_{3}-\mathrm{H}+2 \mathrm{H}$ in 3-oxo- $\Delta^{4}$ steroids without a hydroxyl group at C-7; or $\mathrm{b}_{3}-\mathrm{C}_{2} \mathrm{H}_{4}$ from $\mathrm{b}_{2}-\mathrm{CH}_{3}-\mathrm{H}+\mathrm{H}+\mathrm{OH}$ in 7-hydroxy-3-oxo- $\Delta^{4}$ steroids ions. To elucidate further the structure of these ions, 3-oxo- $\Delta^{4}$ steroids labeled with ${ }^{13} \mathrm{C}$ at $\mathrm{C}-7$ or $\mathrm{C}-10$ should be analyzed.

While the B-ring fragment ions are the dominant cleavage products of the steroid skeleton, fragment ions important in the structural identification of 3-oxo- $\Delta^{4}$ sterol GP hydrazones are formed by additional cleavage in the Cand D-rings, and in the C-17 side-chain. For example, the enhanced abundance of fragment ions at $\mathrm{m} / \mathrm{z} 325.26$ and 353.26 in the CID spectrum of a monohydroxy-3-oxo- $\Delta^{4}$ $\mathrm{C}_{27}$ steroid $(\mathrm{m} / \mathrm{z}$ 534.41) are indicative of a 24-hydroxyl group, and correspond to ${ }^{*} \mathrm{f}-\mathrm{H}$ and ${ }^{*} \mathrm{f}-\mathrm{H}$ fragments (Figure $2 \mathrm{a}, \mathrm{b}$, and h upper panels, Figure 5a, Scheme 2). Similarly, the presence of the 25-hydroxyl group in $\mathrm{C}^{4}$-25-ol-3-one GP hydrazone (VII) can be identified by enhanced abundance of ${ }^{*} \mathrm{~h}-\mathrm{H}$ and ${ }^{*} \mathrm{~h}-\mathrm{H}$ ions at $\mathrm{m} / \mathrm{z} 353.30$ and 381.29 (Figure 2c, h right central panel), while an abundant ion at $327.24\left({ }^{*} \mathrm{e}+\mathrm{H}\right)$ is indicative of the 27-hydroxyl group (Figure 2d). Although these three isomers, and additionally the 7-hydroxy isomers, can be differentiated at lowresolution on the tandem quadrupole from the above peak patterns, the identity of the fragment ions requires the acquisition of spectra at "moderate"- to "high"-resolution. 
The value of recording MS/MS spectra at highresolution, and the ability to accurately measure peak centroids, is nicely illustrated in the CID spectra $C^{4}-24$ ol-3-one GP hydrazone (VI, Figures 1 and 2h). Shown in Figure $2 \mathrm{~h}$ (upper panels) are expanded views of the peaks in the $\mathrm{m} / \mathrm{z} 325$ and 353 regions recorded at "high-resolution" ( 16,000 FWHM) on the Q-TOF instruments. At this resolution peaks at $m / z 325.23$ and 325.26 are fully resolved, respectively. By centroiding the respective peaks, elemental compositions of $\mathrm{C}_{21} \mathrm{H}_{29} \mathrm{~N}_{2} \mathrm{O}\left({ }^{*} \mathrm{e}-\mathrm{H}\right)$ and $\mathrm{C}_{22} \mathrm{H}_{33} \mathrm{~N}_{2}\left({ }^{\#} \mathrm{f}-\mathrm{H}\right)$ are determined. Even when spectra are recorded at "moderate" resolution $(12,000)$, the accurate mass values are within 10 ppm of the theoretical mass values for these elemental formulas (data not shown). In the $\mathrm{m} / \mathrm{z} 353$ region, just one peak is observed at $\mathrm{m} / \mathrm{z} 353.26$ corresponding to an elemental composition $\mathrm{C}_{23} \mathrm{H}_{33} \mathrm{~N}_{2} \mathrm{O}\left({ }^{*} \mathrm{f}-\mathrm{H}\right)$, and not surprisingly the centroid of this fully resolved peak gives good agreement with the theoretical mass (2 ppm). The ability of the Q-TOF instruments to resolve close lying peaks and accurately measure their position on the $\mathrm{m} / \mathrm{z}$ scale is of great value in identifying ion structure. Further, a knowledge of the elemental composition of the precursor ion (determined in an independent mass scan), e.g., $\mathrm{C}_{34} \mathrm{H}_{52} \mathrm{~N}_{3} \mathrm{O}_{2}$ for $\mathrm{C}^{4}$-24-ol-3-one GP hydrazone (VI), is used to limit the chemical composition of possible fragment ions in a search of measured mass against elemental composition. This improves the specificity of the search, and effectively means that a mass accuracy of $10 \mathrm{ppm}$ can allow the unique identification of most fragment ions.

Most fragment ions in the CID spectra of 3-oxo- $\Delta^{4}$ GP hydrazones are derived from $[\mathrm{M}-79]^{+}$or $[\mathrm{M}-107]^{+}$ intermediates (Scheme 2). Those derived from the $[\mathrm{M}-79]^{+}$intermediate (indicated by an asterisk) are modified by the addition of the $\mathrm{NNHCOCH}_{2}$ group $(71.0245 \mathrm{Da})$ to the steroid skeleton, while those derived from the $[\mathrm{M}-107]^{+}$intermediate (indicated by a hatch, ${ }^{*}$ ) are modified with a $\mathrm{NNHCH}_{2}$ group (43.0296). These "groups" or "tags" are mass deficient with respect to moieties made up simply of carbon and hydrogen. Taking the $\mathrm{NNHCOCH}_{2}(71.0245 \mathrm{Da})$ tag for example, the hydrocarbon closest in mass is $\mathrm{C}_{5} \mathrm{H}_{11}$ at $71.0861 \mathrm{Da}$, $61.6 \mathrm{mDa}(867 \mathrm{ppm})$ away from the tag. Additionally, the two tags have different degrees of mass deficiency, the result of which is that at a given nominal mass, e.g., 325 (Figure 2h), fragment ions tagged with NNH$\mathrm{COCH}_{2}$ (i.e., ${ }^{*}$ e- $\mathrm{H}, 325.2280 \mathrm{Da}$ ) are resolved from those tagged with $\mathrm{NNHCH}_{2}$ (i.e., ${ }^{\#}$ f-H, $325.2644 \mathrm{Da}$ ) or any possible hydrocarbon fragments (i.e., $\mathrm{C}_{24} \mathrm{H}_{37}, 325.2895$ $\mathrm{Da})$.

As with the monohydroxy-3-oxo- $\Delta^{4}$ steroids, the MS/MS spectra of the dihydroxy-3-oxo- $\Delta^{4}$ GP hydrazones studied allowed isomer differentiation. The presence of a 7-hydroxyl group is immediately evident by the altered pattern of B-ring fragments. Somewhat surprisingly, the $C^{4}-7 \alpha, 25$-diol-3-one (XIII) isomer gives a noticeably different spectrum to the $C^{4}-7 \beta, 25$-diol-3one (XIV) isomer (see Supplementary Material Figure
$\mathrm{S}-1)$. In the spectrum of the $7 \alpha$ isomer there is enhanced abundance of the fragment ions at $\mathrm{m} / \mathrm{z} 203.15\left({ }^{\#} \mathrm{C}_{2}+\right.$ $\left.2 \mathrm{H}-\mathrm{H}_{2} \mathrm{O}\right)$ and $231.15\left({ }^{*} \mathrm{C}_{2}+2 \mathrm{H}-\mathrm{H}_{2} \mathrm{O}\right)$, while in the spectrum of the $7 \beta$ isomer the fragment ion at $341.22\left({ }^{*} \mathrm{e}-\mathrm{H}\right)$ is enhanced. Significantly, there is also a major difference in the relative abundance of $[\mathrm{M}-79-18]^{+}$and [M-107-18] $^{+}$ions between these isomers, in that the dehydration products $(\mathrm{m} / \mathrm{z} 453.15,425.35)$ are more prevalent in the spectrum of the $7 \beta$ isomer. The presence of the $7 \alpha$-hydroxyl group in $C^{4}-7 \alpha, 27$-diol-3-one $(\mathbf{X V})$ also affects the fragment ion ratio of ions at $\mathrm{m} / \mathrm{z}$ 203.15, 231.15, and 341.22 in that the abundance of ions at 203.15 and 231.15 are enhanced (Figure 3a). This isomer can then be differentiated from the $7 \beta, 25$-diol on account of the abundance of these fragment ions, and from the $7 \alpha, 25$-diol on account of the abundance of [M-79-18] $]^{+}$fragment $(\mathrm{m} / \mathrm{z}$ 453.35). The presence of the 25-hydroxyl group results in enhanced dehydration of the $[\mathrm{M}-79]^{+}$fragment ion. The lability of the 25-hydroxyl group also enhances the abundance of fragment ions at $m / z 363.31\left(\mathrm{C}_{27} \mathrm{H}_{39}\right)$ compared with that at 381.32 $\left(\mathrm{C}_{27} \mathrm{H}_{41} \mathrm{O}\right)$, corresponding to quadruply unsaturated cholestane and triply unsaturated cholestanol skeletons, respectively (cf. Scheme 5). The MS/MS spectrum of $\mathrm{C}^{4}-20 \mathrm{R}, 22 \mathrm{R}$-diol-3-one (XII) is quite different from that of isomers possessing a 7-hydroxyl group on account of the pattern of B-ring fragments. Additionally, the presence of the 20,22-diol structure gives enhanced abundance of ions at $m / z 299.25\left({ }^{\#} \mathrm{e}+\mathrm{H}\right), 327.24\left({ }^{*} \mathrm{e}+\mathrm{H}\right)$ and $353.26\left({ }^{*} \mathrm{f}+\mathrm{H}-\mathrm{H}_{2} \mathrm{O}\right)$ (Figure $\left.3 \mathrm{~b}\right)$. The 20,22-diol structure is further characterized by an abundant fragment ion at $\mathrm{m} / z 109.10\left(\mathrm{C}_{8} \mathrm{H}_{13}\right)$. This ion corresponds to a side-chain fragment formed by cleavage of the C-17C-20 bond, and which is additionally doubly unsaturated by loss of the two water molecules. This ion is complementary to e-type fragments. The absence of an abundant ion at $\mathrm{m} / \mathrm{z} 109.10$ in the MS/MS of the dihydroxy-3-oxo- $\Delta^{4}$ steroid GP hydrazone in the brain sample analyzed (Figure $5 \mathrm{~b}$ and Supplementary Material Figure S-1f) argues against it being a 20,22-diol, and the pattern of B-ring fragment ions definitely indicates that the steroid is not 7-hydroxylated. We tentatively suggest a 24,25 -diol, a $24,27-$ diol or a 25,27 -diol structure (Figure $5 \mathrm{~b}$ and Supplementary Material Figure $\mathrm{S}-1 \mathrm{f})$. The presence of multiple isomers in the brain sample emphasizes the importance of incorporation of the LC-MS/MS step (Figure 5).

Although only one dioxosteroid was analyzed in the current study, i.e., $\mathrm{C}^{4}-3,20$-dione, the MS/MS spectra of both the bis- and mono-GP hydrazones $(\mathbf{X}, \mathbf{X I})$ give fragment ion information which aid in the location of the two oxo groups. In earlier studies, we have observed that GP hydrazine reacts faster with the 3-oxo- $\Delta^{4}$ structure than with simple ketones, and the MS/MS spectrum of the $\mathrm{C}^{4}-3,22$-dione mono-GP $(\mathbf{X})$ confirms this, i.e., the pattern of $b_{1}-12, b_{2}-C_{2} / b_{3}-C_{2} H_{4}$ and $b_{2}$ $\mathrm{B}$-ring fragment ions is observed (Figure 2f). Additionally, the location of the C-22 ketone is indicated by the abundant ${ }^{*} \mathrm{e}-\mathrm{H}$ and ${ }^{*} \mathrm{e}-\mathrm{H}$ fragments $(\mathrm{m} / \mathrm{z} 2297.23,325.23)$ 
formed by a McLafferty-type fragmentation of the bond $\beta$ to the ketone group. The low-mass region of the spectrum also gives fragment ions indicative of the 22-oxo group, i.e., at $m / z$ 99.08, $\left(\mathrm{C}_{6} \mathrm{H}_{11} \mathrm{O}, \mathrm{F}\right)$ and 81.07, $\left(\mathrm{C}_{6} \mathrm{H}_{9}, \mathrm{~F}-\mathrm{H}_{2} \mathrm{O}\right)$. These are cations formed by cleavage of the $\mathrm{C}-20-\mathrm{C}-22$ bond $\alpha$ to the ketone group, without and with dehydration (cf. Scheme 5). The observation of these structurally informative low-mass fragment-ions emphasizes the importance of recording the entire MS/MS spectrum, not just a portion of it (cf. ion-trap data). Inspection of the MS/MS spectrum of the bisderivative (Figure $2 \mathrm{~g}$ ) reveals a very minor pattern of B-ring fragments, and a structurally significant fragment at $m / z 353.26\left({ }^{*} \mathrm{f}-\mathrm{H}\right)$ formed by cleavage of the C-20-C-22 bond. Most of the spectrum is dominated by fragment ions formed by cleavages through the hydrazone groups, which are less structurally informative, but are of value for neutral-loss scanning.

The low-mass region of the MS/MS spectra of steroid GP hydrazones is particularly informative when the C-17 side-chain contains two hydroxyl groups (Figure $3 b$ ), or an unsaturated group. This is evident in the spectra of $C^{4}$-3,22-dione $(\mathbf{X})$ and $C^{4,22}-24 \beta$-ethyl-3-one (IV) (Figures 2f, 3d). The presence of the C-22-C-23 double-bond in the $\mathrm{C}^{4,22}$-24 $\beta$-ethyl-3-one (IV) structure results in an abundant fragment at $m / z 83.09\left(\mathrm{C}_{6} \mathrm{H}_{11}\right)$ formed by cleavage of the C-23-C-24 bond.

\section{Sensitivity of Analysis}

Without derivatization, oxysterols are difficult to analyze by mass spectrometry. Traditionally, oxysterols are analyzed by GC-MS after derivatization of the hydroxyl groups to trimethylsilyl ethers [31, 32]; alternatively cholesterol-like molecules can be analyzed by ES-MS and ES-MS/MS after one of a number of different derivatization reactions [53]. In the current study, molecules with a $C^{5}-3 \beta$-ol structure have been oxidized to 3-oxo- $\Delta^{4}$ steroids and then derivatized to GP hydrazones. Steroids with $C^{5}-3 \beta$-ol structure are extremely insensitive to ES ionization, and are only observed on the $100 \mathrm{ng}$ level, 3-oxo- $\Delta^{4}$ steroids give $[\mathrm{M}+\mathrm{H}]^{+}$ions and can be observed on the 500 pg level, but further derivatization to their GP hydrazones gives sub-pg sensitivity.

As with all analytical methods, there are advantages and disadvantages; in an attempt to provide an even handed discussion we draw the attention of the reader to the following: Only $3 \beta$-hydroxy- $\Delta^{5}$ and $3 \beta$-hydroxy- $5 \alpha$ steroids are oxidized by cholesterol oxidase, however, steroid dehydrogenases are available that can be used for other isomers. Oxysterols with a second substituent in the A-ring are oxidized slowly or perhaps not at all by cholesterol oxidase. Polyketonic oxysterols may give multiple derivatives with one or several GP groups; oxysterols containing an oxo group formed in vitro should then be analyzed before and after treatment with cholesterol oxidase.

The true value of the current procedure is most effectively illustrated by the fact that a high quality MS/MS spectrum of oxidized and derivatized 24-hydroxycholesterol were obtained when a sample corresponding to oxysterols extracted from only $40 \mu \mathrm{g}$ of brain tissue was loaded into the ES capillary or onto $C_{18}$ capillary column. When the extraction, oxidation and derivatization procedures have been fully optimized it can be expected that the amount of tissue required could be reduced further. This degree of sensitivity makes oxysterol analysis from tissue biopsies a real possibility.

\section{Acknowledgments}

This work was supported by the UK Biotechnology and Biological Sciences Research Council (BBSRC grant no. BB/C515771/1), The School of Pharmacy, University of London, the Swedish Research Council (VR grant no. 03X-12,551), and Karolinska Institutet. The British Mass Spectrometry Society is thanked for additional support of the project.

\section{References}

1. Björkhem, I.; Meaney, S.; Diczfalusy, U. Oxysterols in human circulation: Which role do they have? Curr. Opin. Lipidol. 2002, 13, 247-253.

2. Björkhem, I.; Diczfalusy, U. Oxysterols, friends, foes, or just fellow passengers? Arterioscler. Thromb. Vasc. Biol. 2002, 22, 734-742.

3. Axelson, M.; Mörk, B.; Sjövall, J. Occurrence of $3 \beta$-hydroxy-5-cholestenoic acid, $3 \beta, 7 \alpha$-dihydroxy-5-cholestenoic acid, and $7 \alpha$-hydroxy-3oxo-4-cholestenoic acid as normal constituents in human blood. J. Lipid Res. 1988, 29, 629-641.

4. Zhang, J.; Larsson, O.; Sjövall, J.7 $\alpha$-Hydroxylation of 25-hydroxycholesterol and 27-hydroxycholesterol in human fibroblasts.Biochim. Biophys. Acta 1995, 1256, 353-359.

5. Lund, E.; Andersson, O.; Zhang, J.; Babiker, A.; Ahlborg, G.; Diczfalusy, U.; Einarsson, K.; Sjövall, J.; Björkhem, I. Importance of a novel oxidative mechanism for elimination of intracellular cholesterol in humans. Arterioscler. Thromb. Vasc. Biol. 1996, 16, 208-212.

6. Meaney, S.; Bonfield, T. L. ; Hansson, M.; Babiker, A.; Kavuru, M. S.; Thomassen, M. J. Serum cholestenoic acid as a potential marker of pulmonary cholesterol homeostasis : Elevated levels in patients with pulmonary alveolar proteinosis. J. Lipid Res. 2004, 45, 2354-2360.

7. Babiker, A.; Andersson, O.; Lindblom, D.; van der Linden, J.; Wiklund, B.; Lutjohann, D.; Diczfalusy, U.; Bjorkhem, I. Elimination of cholesterol as cholestenoic acid in human lung by sterol 27-hydroxylase: Evidence that most of this steroid in the circulation is of pulmonary origin. J. Lipid Res. 1999, 40, 1417-1425.

8. Schroepfer, G. J. Oxysterols: Modulators of cholesterol metabolism and other processes. Physiol. Rev. 2000, 80, 361-554.

9. Lehmann, J. M.; Kliewer, S. A.; Moore, L. B.; Smith-Oliver, T. A.; Oliver, B. B.; Su, J. L.; Sundseth, S. S.; Winegar, D. A.; Blanchard, D. E.; Spencer, T. A.; Willson, T. M. Activation of the nuclear receptor LXR by oxysterols defines a new hormone response pathway. J. Biol. Chem. 1997, 272, 3137-3140

10. Janowski, B. A.; Willy, P. J.; Devi, T. R.; Falck, J. R.; Mangelsdorf, D. J. An oxysterol signalling pathway mediated by the nuclear receptor LXR $\alpha$. Nature 1996, 383, 728-731.

11. Forman, B. M.; Ruan, B.; Chen, J.; Schroepfer, G. J.; Evans, R. M. The orphan nuclear receptor $\mathrm{LXR} \alpha$ is positively and negatively regulated by distinct products of mevalonate metabolism. Proc. Natl. Acad. Sci. U.S.A. 1997, 94, 10588-10593.

12. Janowski, B. A.; Grogan, M. J.; Jones, S. A.; Wisely, G. B.; Kliewer, S. A.; Corey, E. J.; Mangelsdorf, D. J. Structural requirements of ligands for the oxysterol liver X receptors LXR $\alpha$ and LXR $\beta$. Proc. Natl. Acad. Sci. U.S.A. 1999, 96, 266-271.

13. Song, C.; Liao, S. Cholestenoic acid is a naturally occurring ligand for liver X receptor $\alpha$. Endocrinology 2000, 141, 4180-4184.

14. Russell, D. W. Nuclear orphan receptors control cholesterol catabolism. Cell 1999, 97, 539-542.

15. Repa, J. J.; Mangelsdorf, D. J. The role of orphan nuclear receptors in the regulation of cholesterol homeostasis. Annu. Rev. Cell Dev. Biol. 2000, 16, $459-481$.

16. Brown, A. J.; Jessup, W. Oxysterols and atherosclerosis. Atherosclerosis 1999, 142, 1-28

17. Lin, Y. Y. Welch, M. Liebermann, S. The detection of 20(S)-hydroxycholesterol in extracts of rat brains and human placenta by a gas chromatograph/mass spectrometry technique. J. Steroid Biochem. Mol. Biol. 2003, 85, 57-61. 
18. Yao, Z.X.; Brown, R. C.; Teper, G.; Greeson, J.; Papadopoulos, V. 22-Hydroxycholesterol protects neuronal cells from $\beta$-amyloid-induced cytotoxicity by binding to $\beta$-amyloid peptide. J. Neurochem. 2002, 83, 1110-1119.

19. Axelson, M.; Larsson, O.; Zhang, J.; Shoda, J.; Sjövall, J. Structural specificity in the suppression of HMG-CoA reductase in human fibroblasts by intermediates in bile acid biosynthesis. J. Lipid Res. 1994, 36, 290-298.

20. Bjorkhem, I.; Reihner, E.; Angelin, B.; Ewerth, S.; Akerlund, J. E.; Einarsson, K. On the possible use of the serum level of $7 \alpha$-hydroxycholesterol as a marker for increased activity of the cholesterol $7 \alpha$ hydroxylase. J. Lipid Res. 1987, 28, 889-894.

21. Axelson, M.; Aly, A.; Sjövall, J. Levels of $7 \alpha$-hydroxy-4-cholesten-3-one in plasma reflects rates of bile acid synthesis in man. FEBS Lett. 1988, $239,324-328$

22. Axelson, M.; Björkhem, I.; Reihner, E.; Einarsson, K. Plasma level of $7 \alpha$-hydroxy-4-cholesten-3-one reflects the activity of hepatic cholesterol $7 \alpha$-hydroxylase in man. FEBS Lett. 1991, 284, 216-218.

23. Björkhem, I.; Diczfalusy, U.; Lütjohann, D. Removal of cholesterol from extrahepatic sources by oxidative mechanisms. Curr. Opin. Lipidol. 1999, 10, 161-165.

24. Lund, E. G.; Guileyaedo, J. M.; Russel, D. W. cDNA cloning of cholesterol 24-hydroxylase, a mediator of cholesterol homeostasis in the brain. Proc. Natl. Acad. Sci. U.S.A. 1999, 96, 7238-7234.

25. Björkhem, I.; Andersson, U.; Ellis, E.; Alvelius, G.; Ellegard, L.; Diczfalusy, U.; Sjövall, J.; Einarsson, C. From brain to bile. Evidence that conjugation and $\omega$-hydroxylation are important for elimination of 24S-hydroxycholesterol (cerebrosterol) in humans. J. Biol. Chem. 2001, 276, 37004-37010

26. Bodin, K.; Bretillon, L.; Aden, Y.; Bertilsson, L.; Broome, U.; Einarsson, C.; Diczfalusy, U. Antiepileptic drugs increase plasma levels of $4 \beta$ hydroxycholesterol in humans: Evidence for involvement of cytochrome P450 3A4. J. Biol. Chem. 2001, 276, 38685-38689.

27. Wentworth, P.; McDunn, J. E.; Wentworth, A. D.; Takeuchi, C.; Nieva, J.; Jones, T.; Bauttista, C.; Ruedi, J. M.; Gutierrez, A.; Janda, K. A.; Babior, B. M.; Eschenmoser, A.; Lerner, R. A. Evidence for antibody-catalyzed ozone formation in bacterial killing and inflammation. Science 2002, 298, 2195-2199.

28. Wentworth, P.; Nieva, J.; Takeuchi, C.; Galve, R.; Wentworth, A. D.; Dilley, R. B.; DeLaria, G. A.; Saven, A.; Babior, B. M.; Janda, K. D. Eschenmoser, A.; Lerner, R. A. Evidence for ozone formation in human atherosclerotic arteries. Science 2003, 302, 1053-1056.

29. Zhang, Q.; Powers, E. T.; Nieva, J.; Huff, M. E.; Dendle, M. A.; Bieschke, J.; Glabe, C. G.; Eschenmoser, A.; Wentworth, P.; Lerner, R. A.; Kelly, J. W. Metabolite-initiated protein misfolding may trigger Alzheimer's disease. Proc. Natl. Acad. Sci. U.S.A. 2004, 101, 4752-4757.

30. Pulfer, M. K.; Murphy, R. C. Formation of biologically active oxysterols during ozonolysis of cholesterol present in lung surfactant. J. Biol. Chem. 2004, 279, 26331-26338.

31. Dzeletovic, S.; Breuer, O.; Lund, E.; Diczfalusy, U. Determination of cholesterol oxidation products in human plasma by isotope dilutionmass spectrometry. Anal. Biochem. 1995, 225, 73-80.

32. Breuer, O.; Björkhem, I. Simultaneous quantification of several cholesterol autoxidation and monohydroxylation products by isotope-dilution mass spectrometry. Steroids 1990, 55, 185-192.

33. Zhang, Z.; Li, D.; Blanchard, D. E.; Lear, S. R.; Erickson, S. K.; Spencer, T. A. Key regulatory oxysterols in liver: analysis as $\Delta^{4}-3$-ketone derivatives by HPLC and response to physiological perturbations. J. Lipid Res. 2001, 42, 649-658.

34. Ogishima, T.; Okuda, K. An improved method for assay of cholesterol 7- $\alpha$-hydroxylase activity. Anal. Biochem. 1986, 158, 228-232.

35. Griffiths, W. J.; Liu, S.; Alvelius, G.; Sjövall, J. Derivatives Revisited: Analysis of Neutral Steroids by ESMS. Proceedings of the 50th ASMS Conference on Mass Spectrometry and Allied Topics; Orlando, FL, June, 2002.

36. Griffiths, W. I.; Alvelius, G.; Liu, S.; Hornshaw, M.; Sjövall, J. Analysis of Oxysterols in Brain. Proceedings of the 52nd ASMS Conference on Mass Spectrometry and Allied Topics; Nashville, TN, May, 2004.

37. Wang, Y.; Alvelius, G.; Liu, S.; Bodin, K.; Hornshaw, M.; Sjövall, J.; Griffiths, W. J. Steroidomics of Brain. Proceedings of the 53rd ASMS Conference on Mass Spectrometry and Allied Topics; San Antonio, TX, June, 2005.

38. Griffiths, W. J.; Liu, S.; Alvelius, G.; Sjövall, J. Derivatization for the characterization of neutral oxosteroids by electrospray and matrixassisted laser desorption/ionization tandem mass spectrometry: The Girard P derivative. Rapid Commun. Mass Spectrom. 2003, 17, 924-935.
39. Griffiths, W. J.; Alvelius, G.; Liu, S.; Sjövall, J.High-energy collisioninduced dissociation of oxosteroids derivatized to Girard hydrazones. Eur. J. Mass Spectrom. 2004, 10, 63-88

40. Shackleton, C. H. L.; Chuang, H.; Kim, J.; de la Torre, X.; Segura, J. Electrospray mass spectrometry of testosterone esters: Potential for use in doping control. Steroids 1997, 62, 523-529.

41. Dharmasiri, K. A. N.; Huang, Z.-H.; Watson, J. T. Derivatives for detection of anabolic ketosteroids by positive electrospray mass spectrometry. Proceedings of the 41st ASMS Conference on Mass Spectrometry and Allied Topics; San Francisco, CA. May, 1993.

42. Lai, C. C.; Tsai, C. H.; Tsai, F. J.; Lee, C. C.; Lin, W. D. Rapid monitoring assay of congenital adrenal hyperplasia with microbore high-performance liquid chromatography/electrospray ionization tandem mass spectrometry from dried blood spots. Rapid Commun. Mass Spectrom. 2001, 15, 2145-2151.

43. Lai, C. C.; Tsai, C. H.; Tsai, F. J.; Wu, J. Y.; Lin, W. D.; Lee, C. C. Monitoring of congenital adrenal hyperplasia by microbore HPLCelectrospray ionization tandem mass spectrometry of dried blood spots. Clin. Chem. 2002, 48, 354-356.

44. Lai, C. C.; Tsai, C. N.; Tsai, F. J.; Wu, J. Y.; Lin, W. D.; Lee, C. C. Rapid screening assay of congenital adrenal hyperplasia by measuring 17 $\alpha$-hydroxyprogesterone with high-performance liquid chromatography/electrospray ionization tandem mass spectrometry from dried blood spots. J. Clin. Lab. Anal. 2002, 16, 20-25.

45. Higashi, T.; Shimada, K. Derivatization of neutral steroids to enhance their detection characteristics in liquid chromatography-mass spectrometry. Anal. Bioanal. Chem. 2004, 378, 875-882.

46. Shoda, J.; Axelson, M.; Sjövall, J. Synthesis of potential $\mathrm{C}_{27}$-intermediates in bile acid biosynthesis and their deuterium-labeled analogs. Steroids 1993, 58, 119-125.

47. Brooks, C. J. W.; Cole, W. J.; Lawrie, T. D. V.; MacLachlan, J.; Borthwick, J. H.; Barrett, G. M. Selective reactions in the analytical characterization of steroids by gas chromatography-mass spectrometry. J. Steroid Biochem. 1983, 19, 189-210.

48. MacLachlan, J.; Wotherspoon, A. T. L.; Ansell, R. O.; Brooks, C. J. W. Cholesterol oxidase: Sources, physical properties, and analytical applications. J. Steroid Biochem. Mol. Biol. 2000, 72, 169-195.

49. Liu, S.; Sjövall, J.; Griffiths, W. J. Analysis of oxosteroids by nanoelectrospray mass spectrometry of their oximes. Rapid Commun. Mass Spectrom. 2000, 14, 390-400.

50. Liu, S.; Sjövall, J.; Griffiths, W. J. Neurosteroids in rat brain: Extraction, isolation, and analysis by capillary column liquid chromatographyelectrospray mass spectrometry. Anal. Chem. 2003, 75, 5835-5846.

51. Wheeler, O. H. The Girard reagents. J. Chem. Educ. 1968, 45, 435-437.

52. Williams, T. M.; Kind, A. J.; Houghton, E.; Hill, D. W. Electrospray collision induced dissociation of testosterone and testosterone hydroxy analogs. J. Mass Spectrom. 1999, 34, 206-216.

53. Griffiths, W. J. Tandem mass spectrometry in the study of fatty acids, bile acids, and steroids. Mass Spectrom. Rev. 2003, 22, 81-152.

54. Lütjohann, D.; Brzezinka, A.; Barth, E.; Abramowski, D.; Staufenbiel, M.; von Bergmann, K.; Beyreuther, K.; Multhaup, G.; Bayer, T. A. Profile of cholesterol-related sterols in aged amyloid precursor protein transgenic mouse brain. J. Lipid Res. 2002, 43, 1078-1085.

55. Clifton, P. M.; Noakes, M.; Sullivan, D.; Erichsen, N.; Ross, D.; Annison, G.; Fassoulakis, A.; Cehun, M.; Nestel. P.Cholesterol-lowering effects of plant sterol esters differ in milk, yoghurt, bread, and cereal. Eur. J. Clin. Nutr. 2004, 58, 503-509.

56. Fahy, D. M. ; O'Callaghan, Y. C.; O'Brien, N. M. Phytosterols: Lack of cytotoxicity but interference with $\beta$-carotene uptake in Caco-2 cells in culture. Food Addit. Contam. 2004, 21, 42-51.

57. Dhar, A. K.; Teng, J. I.; Smith, L. L. Biosynthesis of cholest-5-ene-3 $\beta$, 24-diol (cerebrosterol) by bovine cortical microsomes. I. Neucochem. 1973, 21, 51-60.

58. Meaney, S.; Babiker, A.; Lütjohann, D.; Diczfalusy, U.; Axelson, M.; Björkhem, I. On the origin of cholestenoic acids in human circulation. Steroids 2003, 68, 595-601.

59. Zhang, J.; Akwa, Y.; El-Etr, M.; Baulieu, E. E.; Sjövall, J. Metabolism of 27-, 25-, and 24-hydroxycholesterol in rat glial cells and neurons. Biochem. J. 1997, 322, 175-184.

60. Zhang, J.; Akwa, Y.; Baulieu, E. E.; Sjövall, J. $7 \alpha$-Hydroxylation of 27 -hydroxycholesterol in rat brain microsomes. C. R, Acad. Sci. III 1995, 318, 345-349.

61. Mast, N.; Norcross, R.; Andersson, U.; Shou, M.; Nakayama, K.; Bjorkhem, I.; Pikuleva, I. A. Broad substrate specificity of human cytochrome P450 46A1 which initiates cholesterol degradation in the brain. Biochemistry 2003, 42, 14284-14292. 